\title{
Hygrothermal analyses of the moisture control and energy efficiency potential of an adaptive water-resistive barrier for building envelopes
}

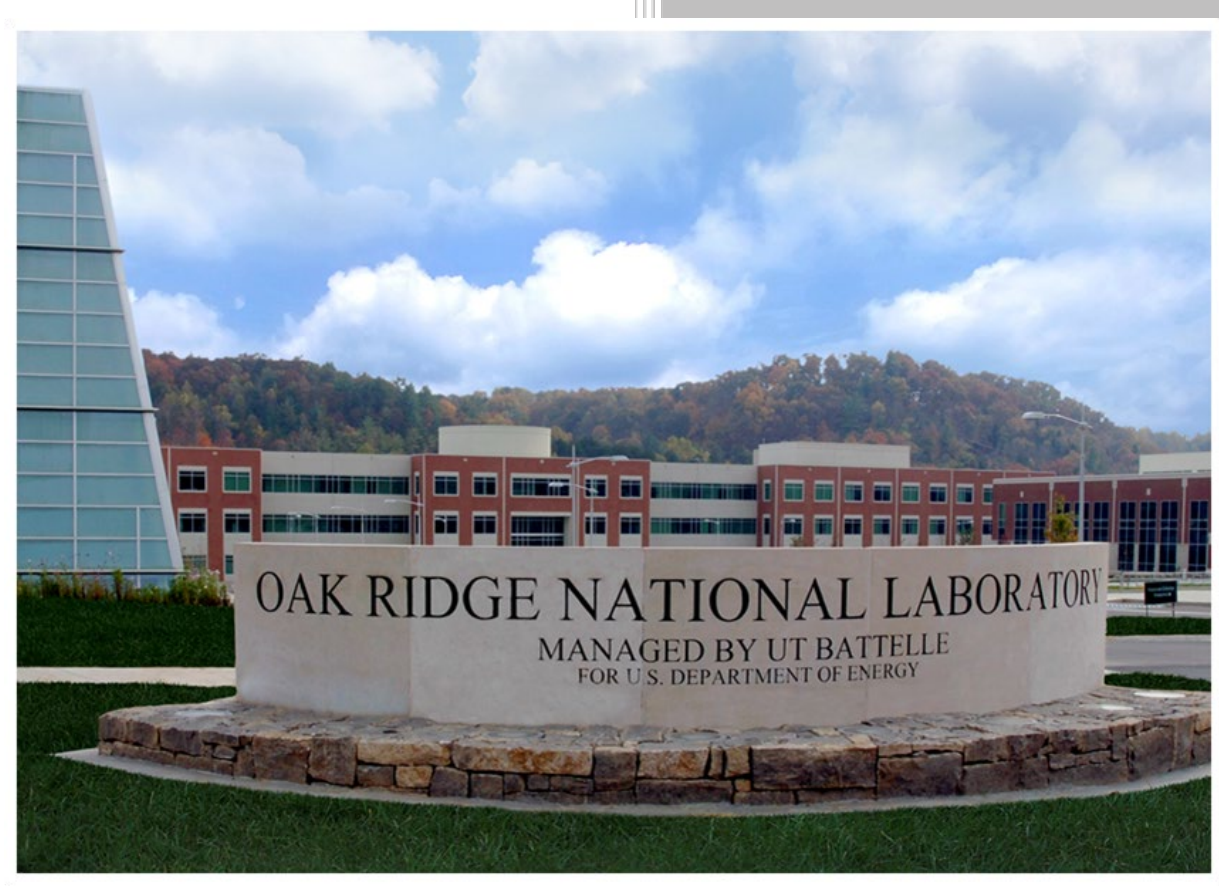

Approved for public release.

Florian Antretter André Desjarlais Diana Hun Distribution is unlimited.

March 15, 2019 


\section{DOCUMENT AVAILABILITY}

Reports produced after January 1, 1996, are generally available free via US Department of Energy (DOE) SciTech Connect.

Website www.osti.gov

Reports produced before January 1, 1996, may be purchased by members of the public from the following source:

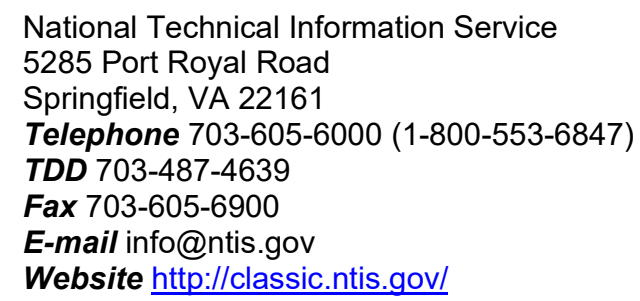

Reports are available to DOE employees, DOE contractors, Energy Technology Data Exchange representatives, and International Nuclear Information System representatives from the following source:

Office of Scientific and Technical Information

PO Box 62

Oak Ridge, TN 37831

Telephone 865-576-8401

Fax 865-576-5728

E-mail reports@osti.gov

Website http://www.osti.gov/contact.html

This report was prepared as an account of work sponsored by an agency of the United States Government. Neither the United States Government nor any agency thereof, nor any of their employees, makes any warranty, express or implied, or assumes any legal liability or responsibility for the accuracy, completeness, or usefulness of any information, apparatus, product, or process disclosed, or represents that its use would not infringe privately owned rights. Reference herein to any specific commercial product, process, or service by trade name, trademark, manufacturer, or otherwise, does not necessarily constitute or imply its endorsement, recommendation, or favoring by the United States Government or any agency thereof. The views and opinions of authors expressed herein do not necessarily state or reflect those of the United States Government or any agency thereof. 
Building Envelope \& Urban Systems Research

Hygrothermal analyses of the moisture control and energy efficiency potential of an adaptive water-resistive barrier for building envelopes

\author{
Florian Antretter \\ André Desjarlais \\ Diana Hun
}

Date Published: March 15, 2019

Prepared by

OAK RIDGE NATIONAL LABORATORY

Oak Ridge, TN 37831-6283

managed by

UT-BATTELLE, LLC

for the

US DEPARTMENT OF ENERGY

under contract DE-AC05-00OR22725 



\section{CONTENTS}

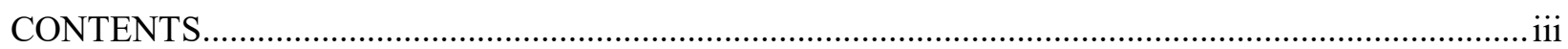

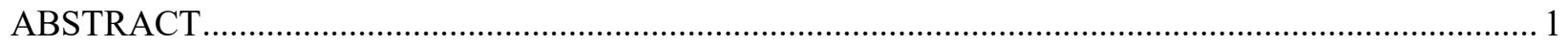

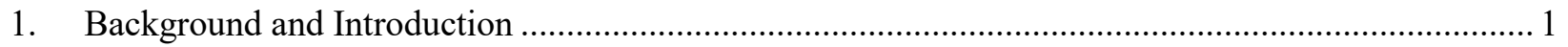

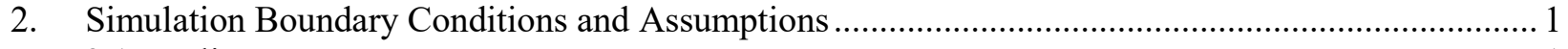

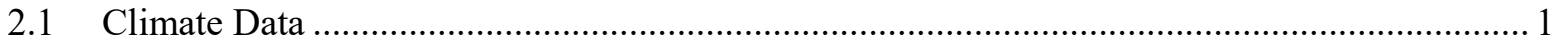

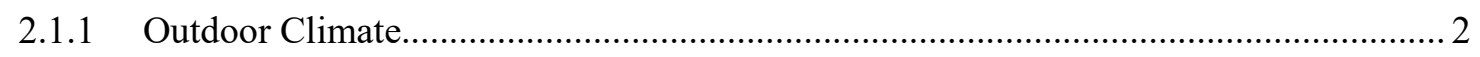

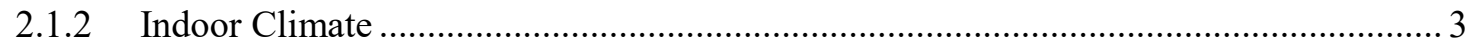

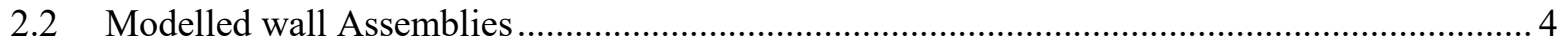

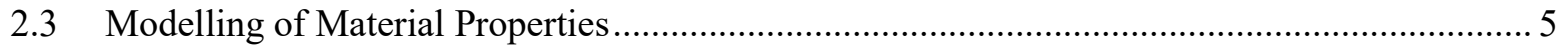

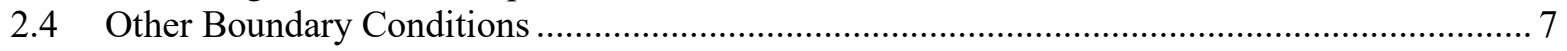

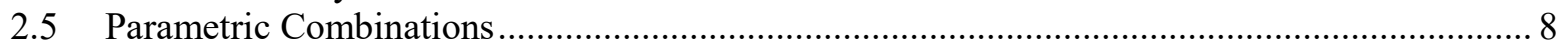

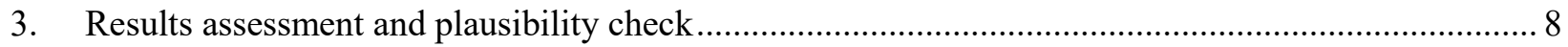

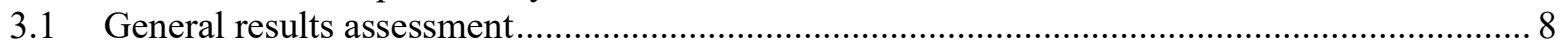

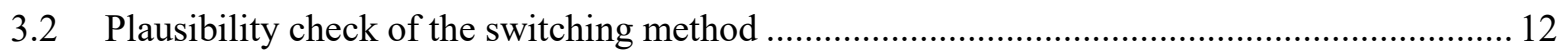

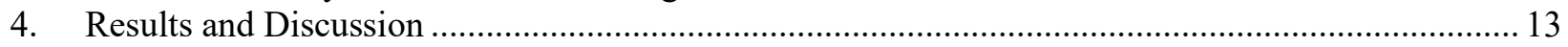

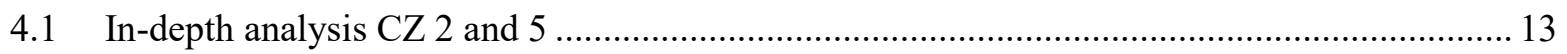

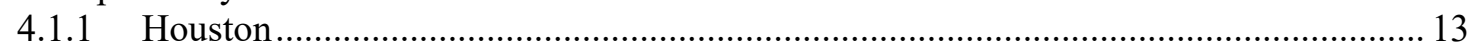

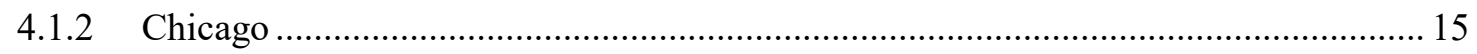

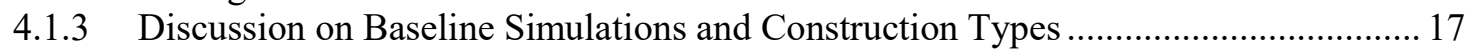

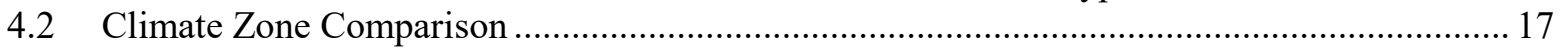

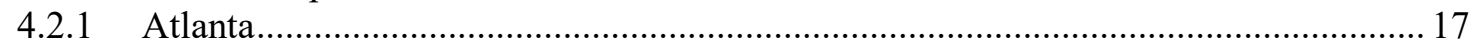

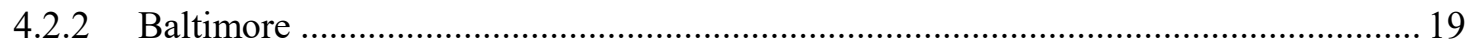

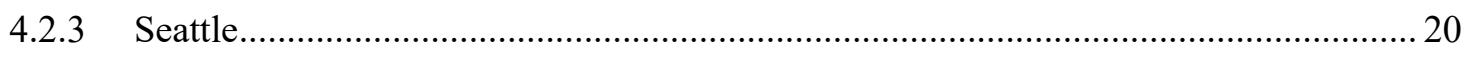

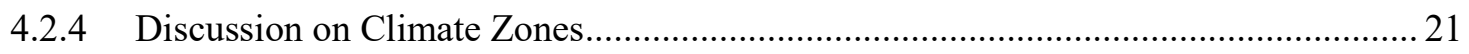

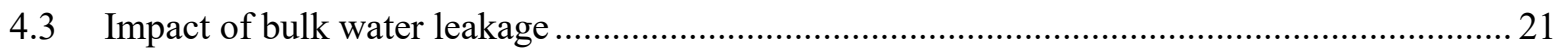

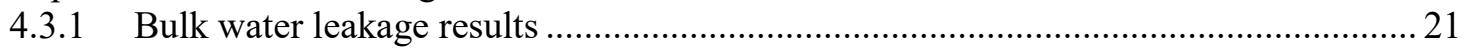

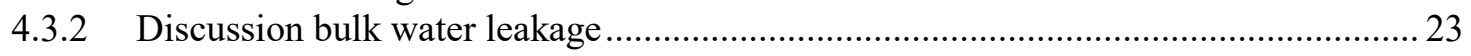

4.4 Impact of permeance options and switching points for switchable membranes ..................... 23

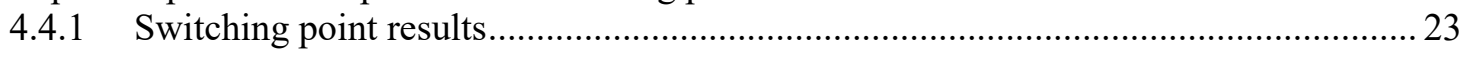

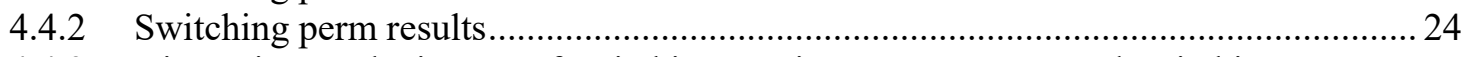

4.4.3 Discussion on the impact of switching maximum permeance and switching

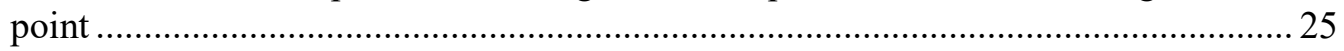

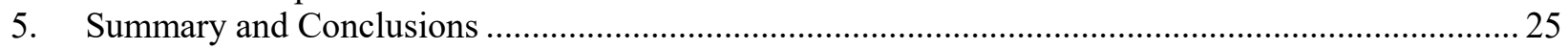

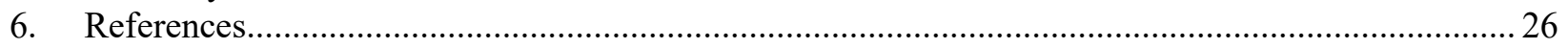




\begin{abstract}
A water-resistive barrier (WRB) is a material installed on the exterior side of the sheathing to prevent water intrusion so that building components are not damaged by moisture. A membrane that can change its water vapor permeability between two states to control water vapor transport into and out of residential and commercial building wall systems is being developed. This simulation study assesses if this membrane used as a WRB reduces moisture levels and mold growth risk in exterior walls and building energy consumption. The developed membrane may require modifications to fully function as a WRB in contact with liquid water.

Hygrothermal component simulations were conducted for different climate zones, different wall assemblies, different switching points and permeabilities to identify the most beneficial application cases and their required perm range and switching control. The study details the required simulation settings and suggests that the switchable membrane can reduce the water content in the sheathing and reduce the mold growth risk in the cavity in all climate zones. The effect on energy consumption of the switchable membrane is not significant. The study also includes recommendations on how to model the material characteristics of a switchable membrane and recommendations on practical applications for the switchable membrane.
\end{abstract}

\title{
1. BACKGROUND AND INTRODUCTION
}

The overall focus of this program is to develop a commercially-viable, adaptive, water-resistive barrier (WRB) membrane to control water vapor transport into and out of residential and commercial building enclosures. The proposed membrane is adaptive in that it can change its vapor permeability between two states - i.e., very low water vapor permeability in one state and high permeability in the other state. As a result of the adaptive feature, when the temperature and relative humidity $(\mathrm{RH})$ outdoors are high, the membrane inhibits the ingress of water vapor into the building. However, if the RH in the wall cavity is high, the membrane will switch to a high permeability state to allow the water vapor to egress to the outside.

The objective of this simulation study is to determine if a WRB membrane that can switch permeability is beneficial from a durability and energy perspective. More specifically, the goals are to determine if such a membrane can reduce moisture levels and mold growth risk in building assemblies, determine the energy impact of such a membrane, and identify the most beneficial application cases and their required perm range and switching control.

\section{SIMULATION BOUNDARY CONDITIONS AND ASSUMPTIONS}

The simulations were carried out with the WUFI® Pro software version 6.2. This hygrothermal component simulation model requires various inputs that are outlined in this chapter.

\subsection{CLIMATE DATA}

The boundary conditions acting on the modelled walls are referred to as "climate data" in this section. These are usually measured weather data for the outdoor climate, and the indoor climate is derived from the exterior conditions with methods described in standards like ASHRAE Standard 160 [1]. 


\subsubsection{Outdoor Climate}

The simulations were performed for the following cities and climate zones $(\mathrm{CZ})$ :

- Houston (CZ 2)

- Atlanta (CZ 3)

- Baltimore (CZ 4)

- Seattle (CZ 4 marine)

- Chicago (CZ 5)

Weather data for those locations is provided in the WUFI ${ }^{\circledR}$ database. For most locations, multiple years of data are available. It was decided to select the so called "ASHRAE Year 3" climate files. The ASHRAE climate files are a result of the ASHRAE RP-1325 [2] and year three identifies the $3^{\text {rd }}$ worst year in terms of hygrothermal impact on building components out of a 30 year dataset.

Examples of these datasets are shown in Figure 1 and Figure 2 for Chicago. Illustrations of the other weather datasets and indoor climate information can be found in Appendix A-1 in Figure 26 to Figure 40.
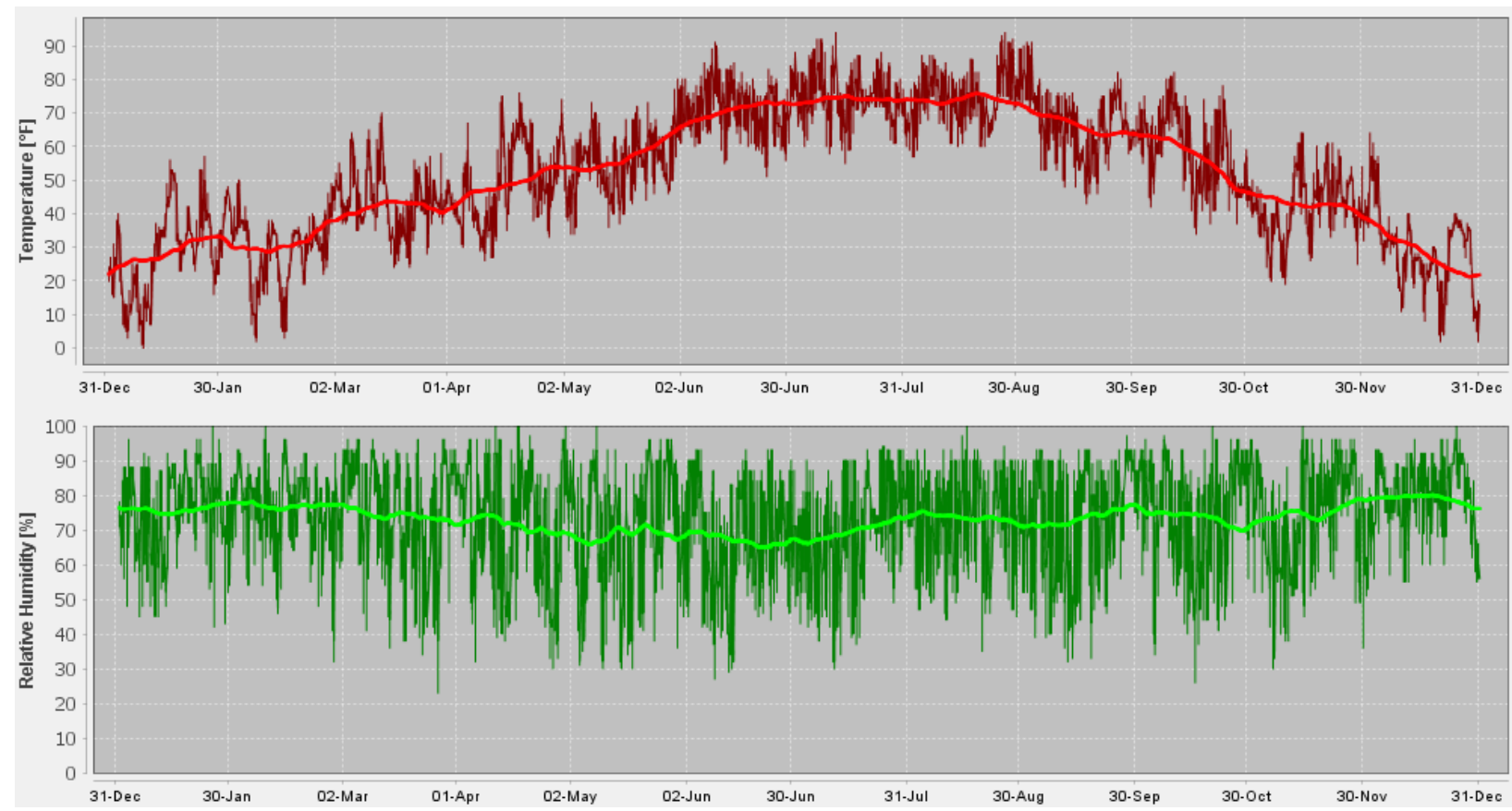

Figure 1: Temperature and relative humidity in the Chicago climate dataset 


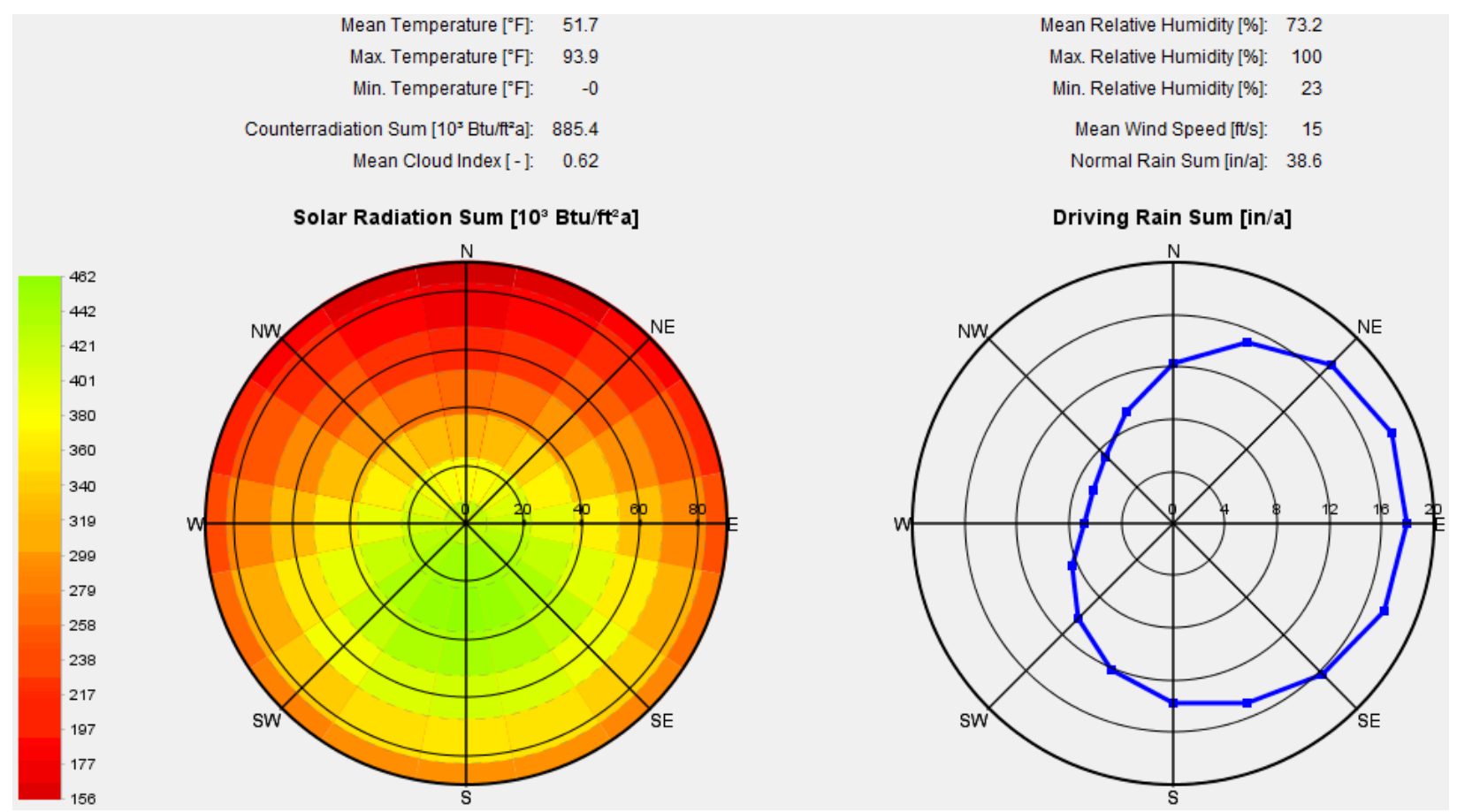

Figure 2: Solar radiation and driving rain in the Chicago climate dataset

\subsubsection{Indoor Climate}

The indoor climate was derived from the outdoor climate with the ASHRAE 160 intermediate method [1]. It was assumed that the indoor climate is controlled with a heat, air conditioning and ventilation (HVAC) system. The specified temperature range was set to values between $21.1{ }^{\circ} \mathrm{C}$ and $23.9{ }^{\circ} \mathrm{C}$. The maximum relative humidity was set to $55 \%$. 


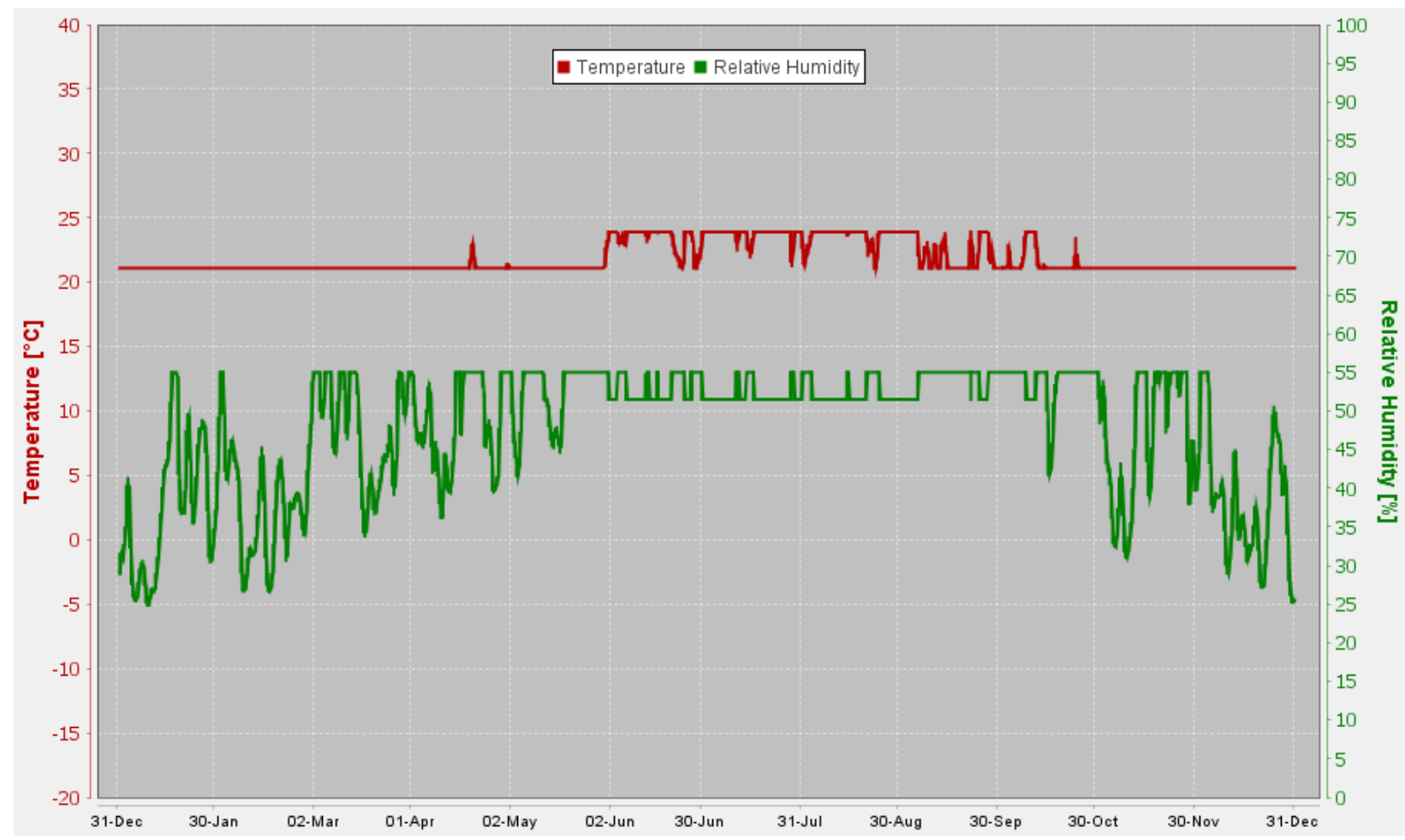

Figure 3: Indoor temperature and relative humidity for Chicago climate

Figure 3 shows the resulting indoor temperature and relative humidity boundary conditions for Chicago. Illustrations of the other indoor climate datasets can be found in Appendix A-1 as well.

\subsection{MODELLED WALL ASSEMBLIES}

The modelled wall assemblies consisted of the following material layers:

- Brick old (4")

- Air Layer (1") ventilated with 50 air changes per hour $(\mathrm{ACH})$ of outdoor air

- WRB (0.5 perm in CZ 2 and 50 perm in CZs 3, 4, and 5)

- Oriented Strand Board or Exterior Gypsum (0.5")

- Glass Fiber Batt Insulation (3.5" in CZ 2 and 5.5" in CZs 3, 4, and 5)

- Kraft Paper as interior vapor retarder in climate zones 3, 4, and 5

- Gypsum Board (USA) with 8 perm interior paint (0.5")

The baseline simulations were conducted with Exterior Gypsum sheathing. Some variants for the Chicago and Houston climates were modelled with Oriented Strand Board sheathing. The insulation thickness was adjusted to fulfil IECC 2015 [3] code requirements which resulted in a 2x4 wall with an R-value of 13 for Houston and a 2x6 wall with an R-value of 20 everywhere else. The modelled assemblies and climate specific settings are shown in Figure 4 and Figure 5.

\begin{tabular}{|l|l|}
\hline Houston & Atlanta, Baltimore, Seattle*, Chicago* \\
\hline$\bullet$ 2x4 with brick cladding & $\bullet$ 2x6 with brick cladding \\
- With 0.5 perm WRB & $\bullet$ With 50 perm WRB \\
- No interior vapor retarder & \\
\hline
\end{tabular}




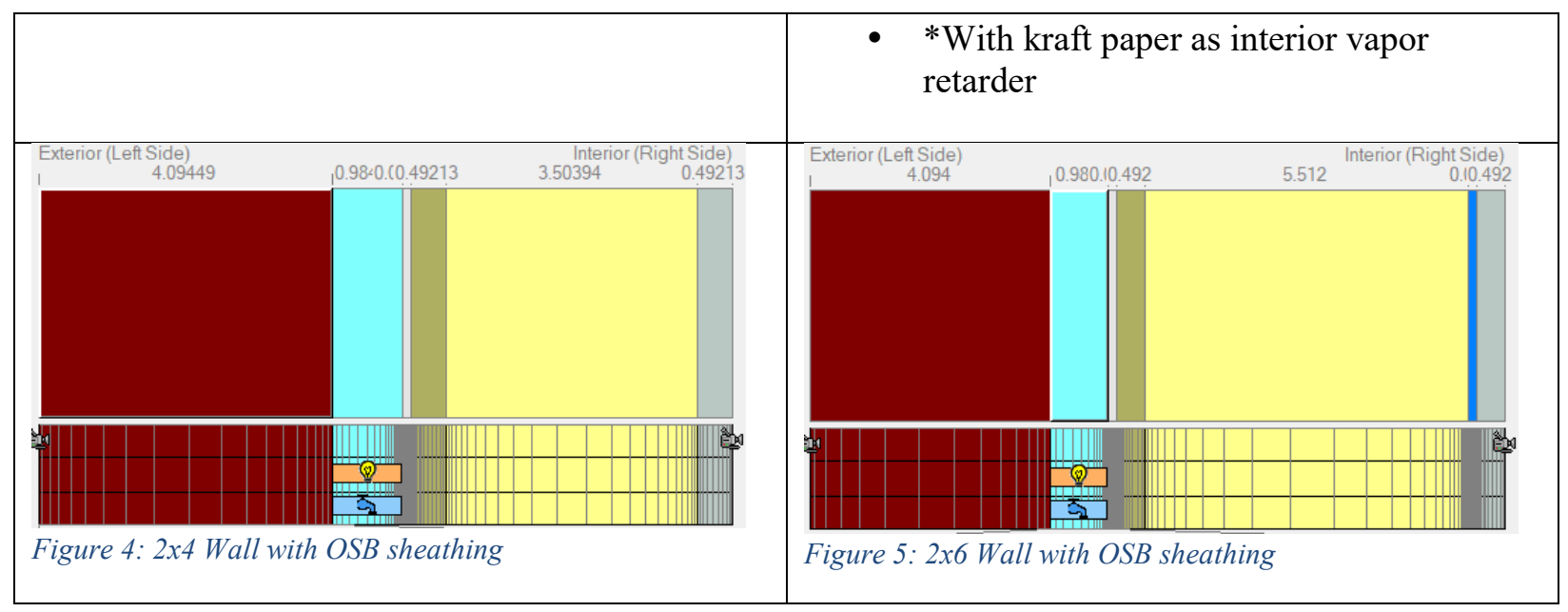

\subsection{MODELLING OF MATERIAL PROPERTIES}

All material properties were chosen from the WUFI ${ }^{\circledR}$ material database according to the previously described material names list in Chapter 2.2. The material properties of the switchable membrane were adjusted from a regular WRB membrane. The important material property of this layer is the water vapor permeability. As thin layers in WUFI need to be modelled with a thickness of at least $1 \mathrm{~mm}$ for reasons of numerical stability, the WRB material properties were converted to a layer of $1 \mathrm{~mm}$ thickness.

From discussions with the project partners, the low and high permeance values of the switchable membrane were set to 0.5 perm and 50 perms (i.e., permeability of 0.02 perm.in and 1.96 perm $\cdot$ in with an assumed material layer thickness of $1 \mathrm{~mm}$ ), respectively. In an initial discussion, it was decided to switch the permeance based on the relative humidity of the exterior sheathing which can be used as a proxy for the moisture content of the material, with a switching point of $80 \%$ relative humidity. Thus, the switchable membrane had a permeance of 50 perms when the RH of the exterior sheathing was lower than $80 \%$ and vice versa as shown in Figure 6.

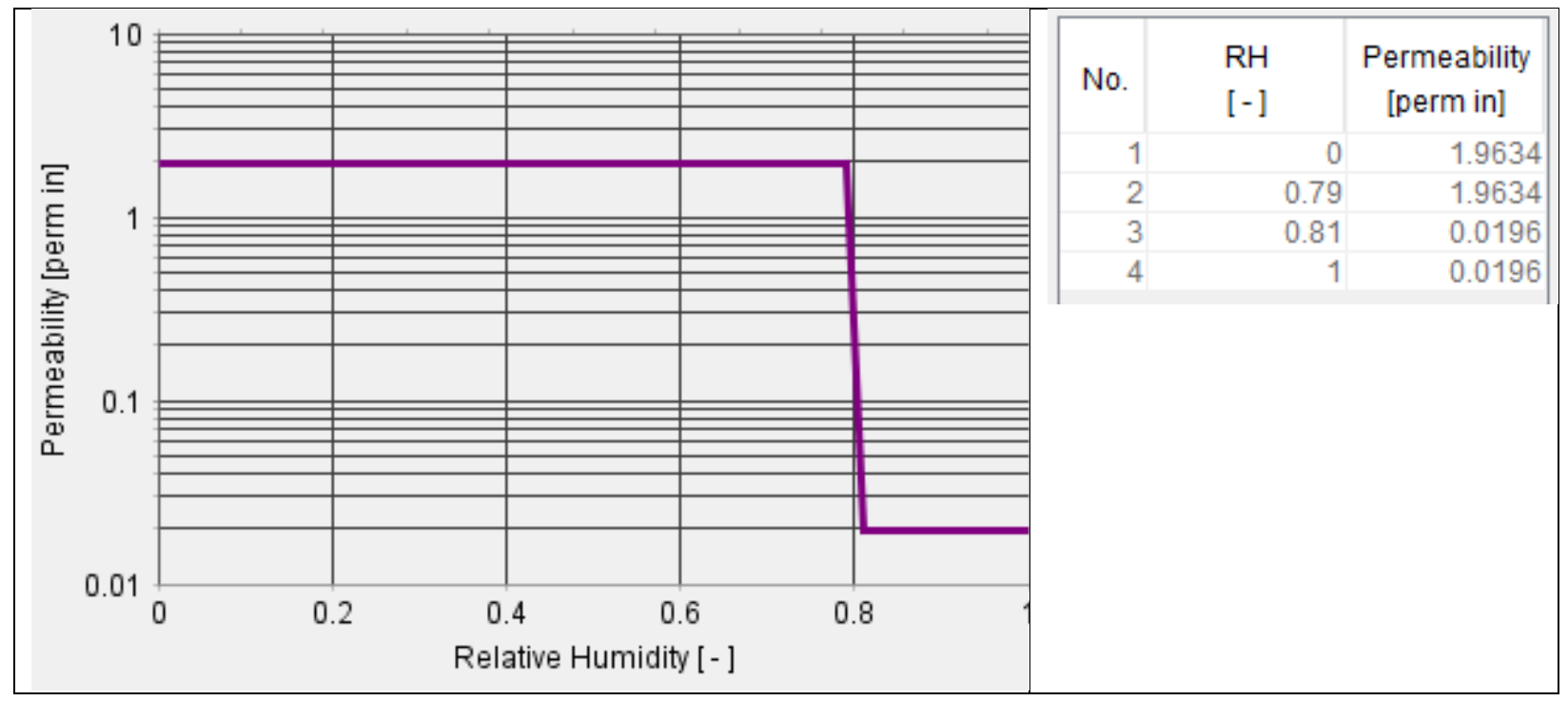


As WUFI ${ }^{\circledR}$ only accepts a dependency of material properties based on conditions right at the specific location inside the material, the originally intended switching control based on the sheathing relative humidity could not be implemented. The control had to be implemented based on the RH inside the membrane. In case the RH drops from above $80 \%$ to below $80 \%$ over the thickness of the material layer, part of the layer (i.e. the switchable membrane) will be modelled as impermeable and part of the layer as permeable, resulting in an only partially/delayed working switch and control. This is visualized in Figure 7.

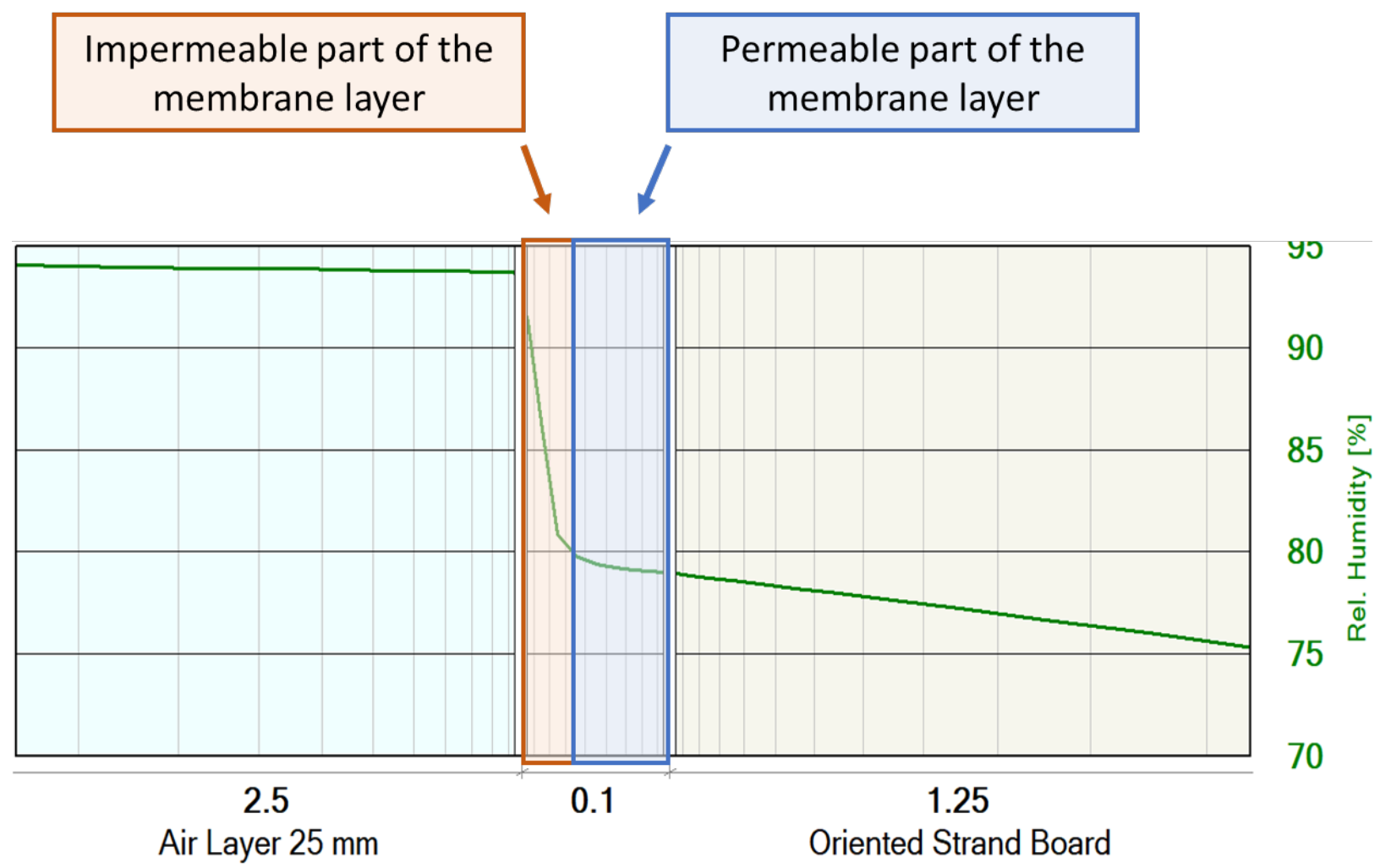

Figure 7: Graphical visualization of a detail of the wall section with a partially switched membrane with an RH drop in the control range over the thickness of the membrane

Therefore, a new approach to model the switchable membrane was developed. As the vapor pressure difference between the sheathing and the air layer should really determine the switch a double layer approach with integrated logic was chosen. With two artificial $1 \mathrm{~mm}$ thick layers with different material properties the desired behavior of the switching membrane could be modelled. For this the permeability of the open and closed state of each of the $1 \mathrm{~mm}$ layers had to be re-computed to represent 50 perms (or the chosen maximum perm value) if both are open and 0.5 perm if both are closed.

The logic was created in a way that:

- Whenever the humidity in the air gap is high and low in the sheathing, the membrane should be closed (less permeable).

- Whenever the humidity in the air gap is low and high in the sheathing, the membrane should be open (permeable). 

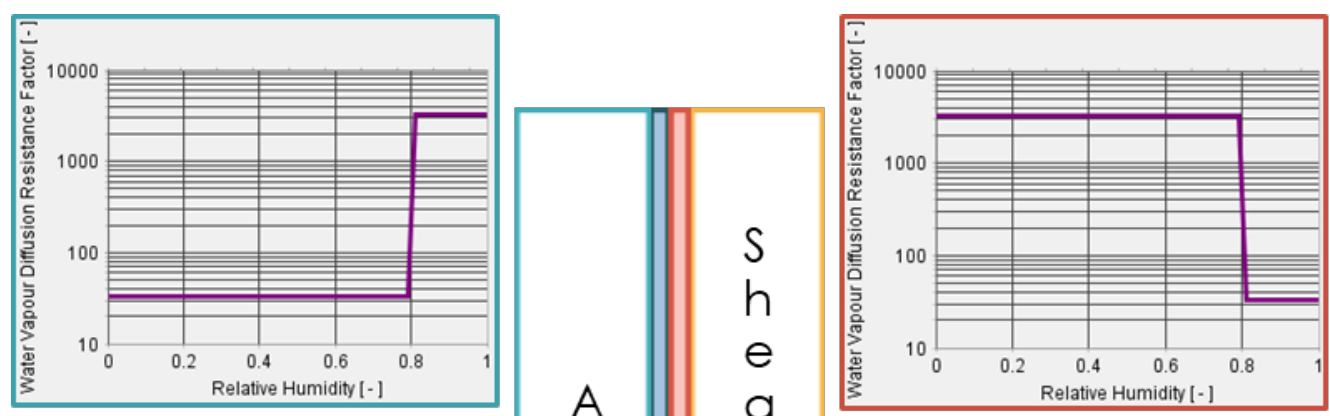

Air Gap

Sheathing

High $\rightarrow$ close
High $\rightarrow$ close

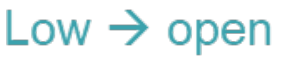

Low $\rightarrow$ open
\& High $\rightarrow$ open

$\&$ Low $\rightarrow$ close

\& High $\rightarrow$ open

$\&$ Low $\rightarrow$ close

\section{Total State}

$=$ impermeable

= impermeable

= permeable

$=$ impermeable

Figure 8: Two-layer approach and resulting logic to model the desired switching behavior

This resulted in the material characteristics and control logic visualized in Figure 8 with a membrane layer with high permeance in humidity ranges below the switching point and low permeance in humidity ranges above the switching point facing the air gap and a second membrane with low permeance in humidity ranges below the switching point and high permeance in humidity ranges above the switching point facing the sheathing. As a result, the two above described cases result in a fully open or fully closed membrane as desired. However, there are also intermediate closed states (with half the closed permeability) whenever humidities of the air layer and the sheathing are either both low or both high.

\subsection{OTHER BOUNDARY CONDITIONS}

Further boundary conditions for the simulation are:

- Default surface transfer resistances for walls

- Default rain load on walls according to ASHRAE 160, but orientation of the wall towards the direction with highest rain loads (all East, except Seattle where it is South)

- Short-wave radiation absorptivity: 0.68 (for a brick wall)

- Initial conditions according to ASHRAE 160 (EMC 80, except brick at two times EMC at 80\% $\mathrm{RH})$

Simulation period: 5 years with hourly time steps and adaptive time step control, starting on October $1^{\text {st }}$ 


\subsection{PARAMETRIC COMBINATIONS}

The parametric set-up for the simulations was designed to compare various cases with WRBs with fixed and switchable permeabilities. The cases assessed how climate zone, type of sheathing (OSB or Gypsum), rain leakage, switching point and the upper switching perm rating impact the effectiveness of the switchable membrane. Table 1 shows the 21 cases that were evaluated.

Table 1: Matrix with all simulation selections

\begin{tabular}{|l|c|c|c|c|c|c|c|c|c|c|c|c|c|c|c|c|}
\hline & \multicolumn{3}{|c|}{ Climate Zone } & \multicolumn{2}{c|}{ Sheathing } & \multicolumn{2}{|c|}{ Leakage } & \multicolumn{3}{c|}{ WRB } & \multicolumn{2}{c|}{ Upper Switching perm } & \multicolumn{2}{c|}{ Switching Point } \\
\hline
\end{tabular}

\section{RESULTS ASSESSMENT AND PLAUSIBILITY CHECK}

\subsection{GENERAL RESULTS ASSESSMENT}

To achieve the goals outlined in chapter 1, several output parameters of the hygrothermal simulation were considered. Figure 9 shows a screenshot of an example of an assembly with the parameters that were used to analyze the simulation results. 


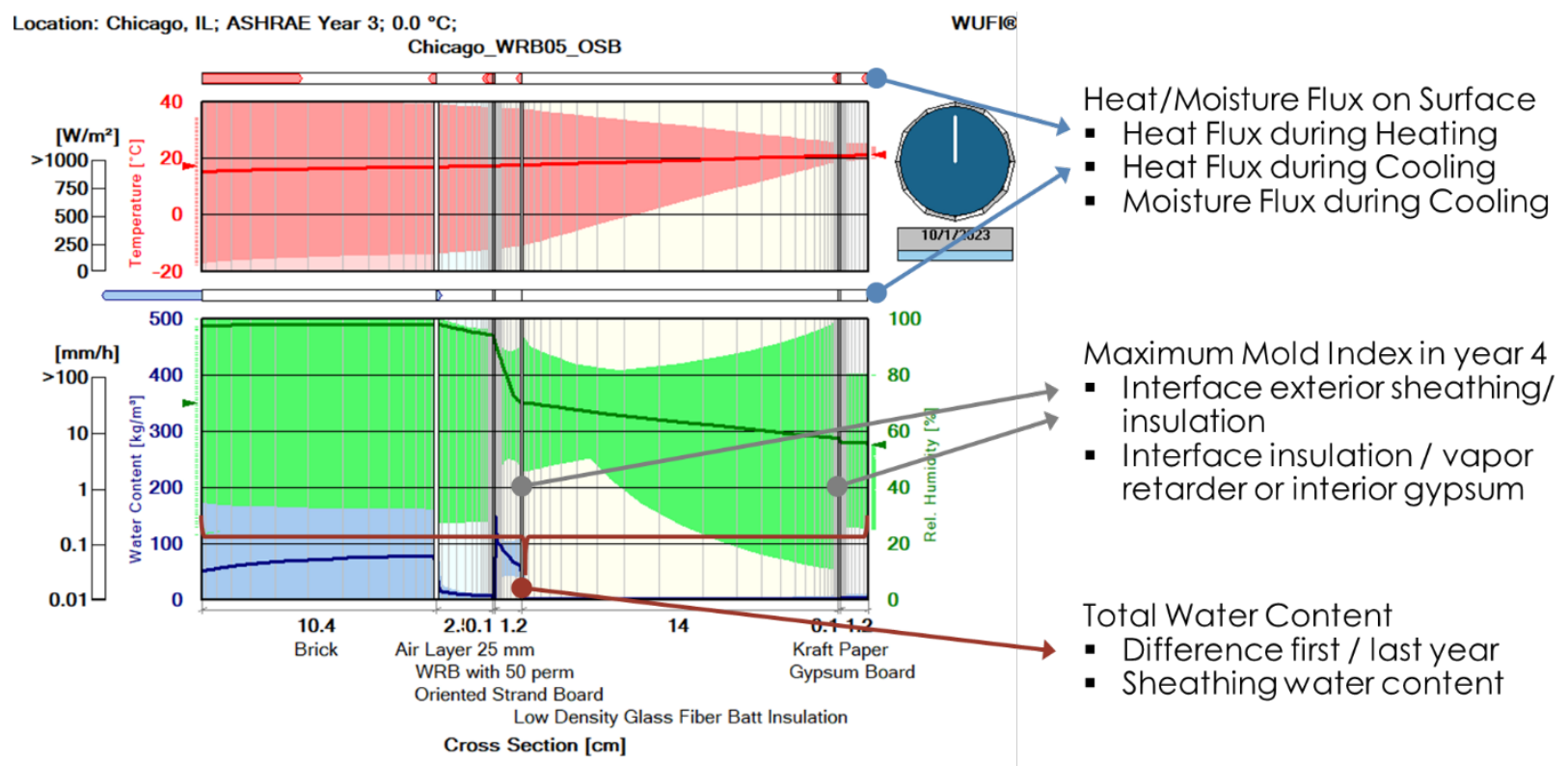

Figure 9: Screenshot of an example of a wall assembly modelled with WUFI with indicators of the simulated parameters that were assessed

Mold growth was assessed at the interface between the sheathing and the insulation in the cavity as well as at the interface between cavity insulation and interior gypsum or vapor retarder. To assess the mold growth, the hourly temperature and relative humidity conditions at that interface are exported to the WUFI VTT postprocessor which uses the VTT Technical Research Center of Finland mold model [4] according to ASHRAE Standard 160 [1]. The settings that were used to assess mold growth were conservative; that is, a sensitive material class and a decline factor of 0.1 were selected. The settings chosen to assess mold growth are shown in Figure 10.

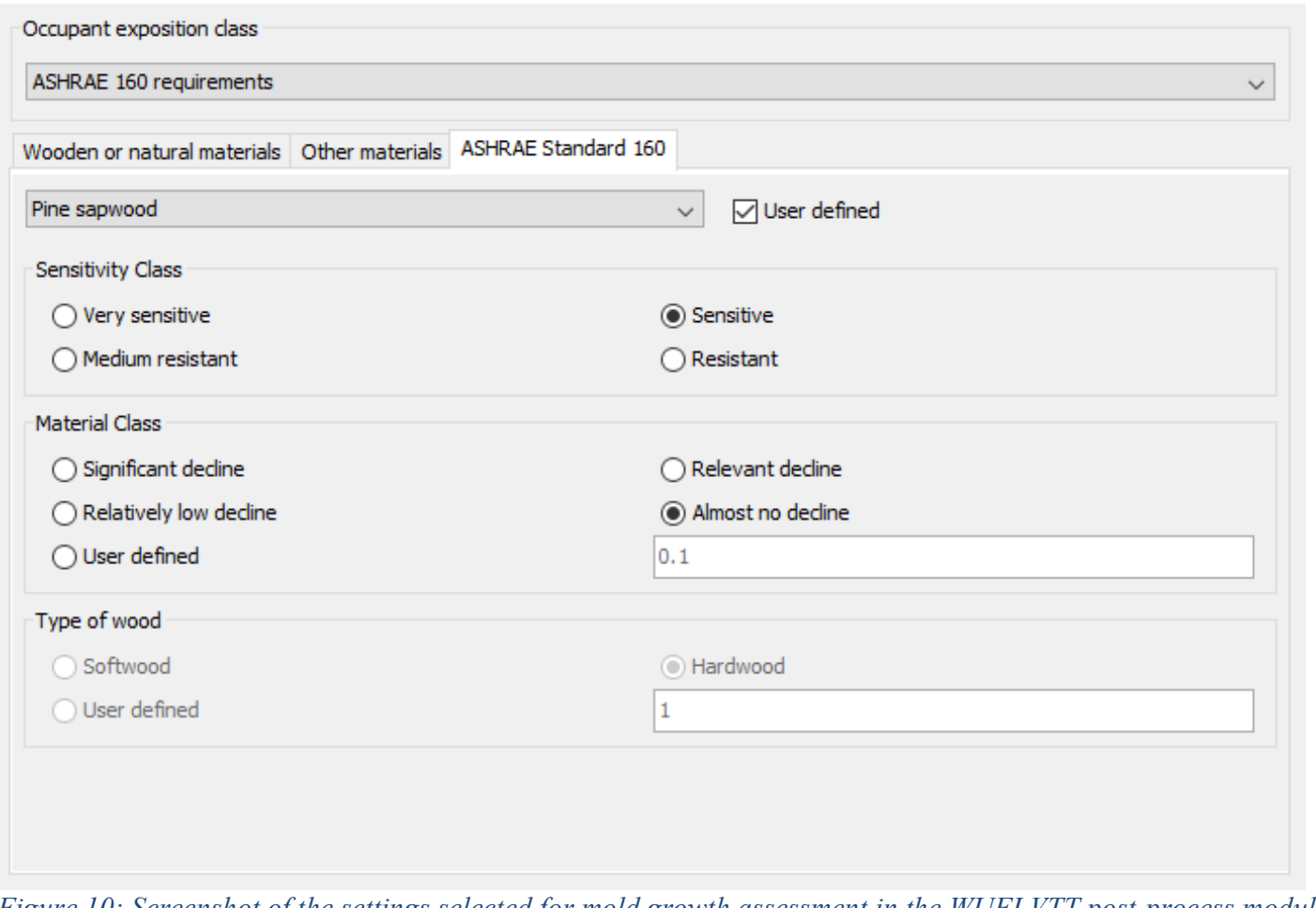

Figure 10: Screenshot of the settings selected for mold growth assessment in the WUFI VTT post-process module 
The maximum mold index (MI) in the fourth full year of the simulations was compared for the 21 cases, i.e. January to December 2022 with a simulation start date of October 2018. A mold index of 0 means no mold growth, maximum mold index is 6 and with a mold index above 3 visible mold growth can be assumed.

Another indicator for moisture related problems is the moisture content (MC) of the sheathing. To compare the cases, the mean moisture content of the sheathing as well as the hours above a certain moisture limit (18 Mass- $\%$ for OSB and 1 Mass- $\%$ for gypsum sheathing) in the fourth year of the simulation were calculated.

The energy impact was determined by looking at the heat flux through the interior surface of the wall. An example of a heat flux density graph is shown in Figure 11. The heat flux must be separated for heating and cooling season. Heating and cooling season are determined by indoor conditions at the set-points. Figure 12 is an example of indoor conditions in Chicago. Negative heat flux density (energy loss from indoors to the wall component) add to heating loads during the heating season (indoor temperatures at lower set-point), positive heat flux density and moisture flux density (sensible or latent heat gain from the wall component to the indoor space) add to the cooling loads during cooling season (indoor temperatures at upper set-point).

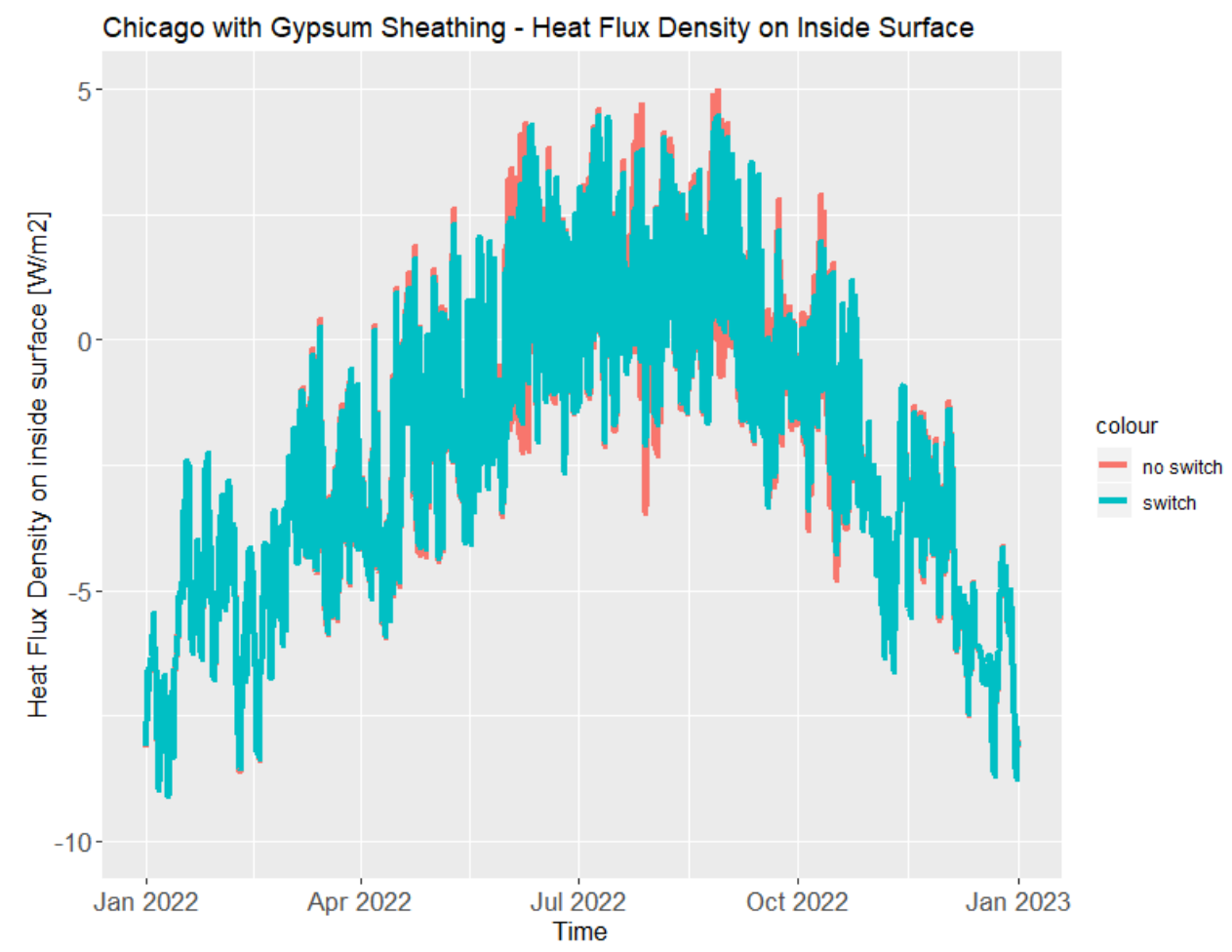

Figure 11: Example of heat flux densities for a wall in Chicago 


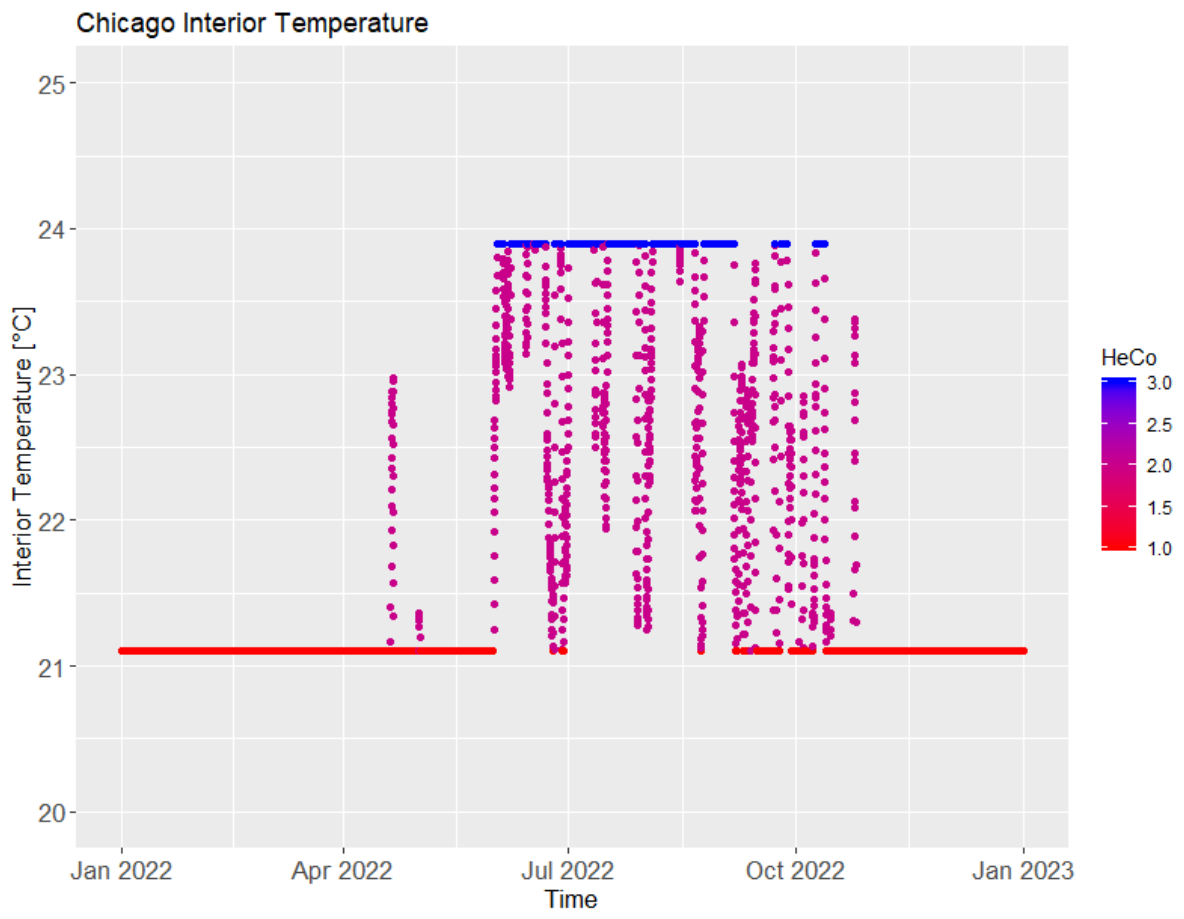

Figure 12: Indoor temperature in Chicago with color code for heating (red), cooling (blue) and free-float (burgundy) times

This analysis results in cumulative gains/losses per year. Figure 13 shows the cumulative heat gains (positive: during cooling season) and heat losses (negative: during heating season) for an example case in Chicago. Figure 14 shows the cumulative moisture flux from the wall into the room for the same example.

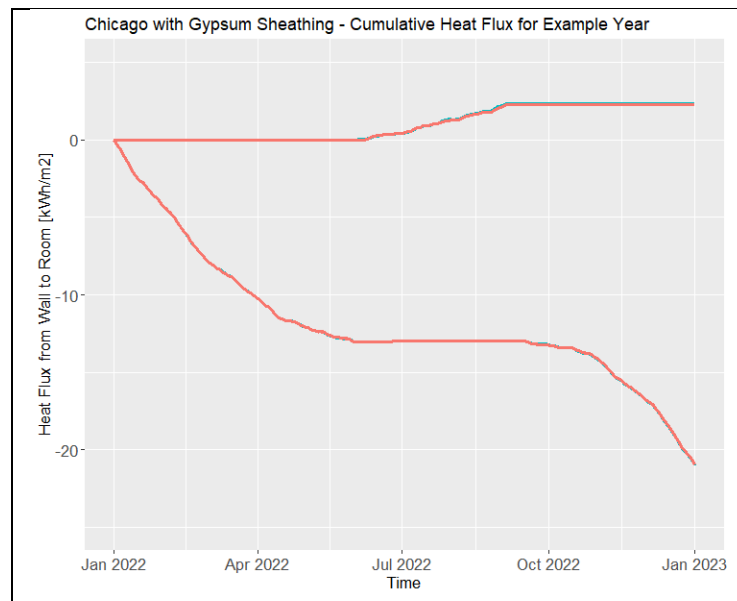

Figure 13: Cumulative sensible heat gains/losses for an example case in Chicago

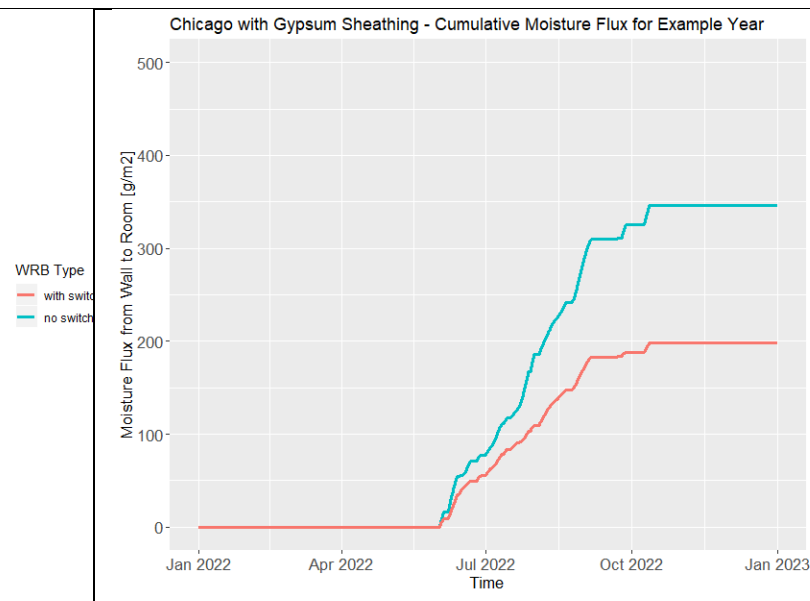

Figure 14: Cumulative latent gains for an example case in Chicago 


\subsection{PLAUSIBILITY CHECK OF THE SWITCHING METHOD}

To check the method to model the switching of the membrane as described in Section 2.3, a plausibility check was conducted. Plotting the moisture flux density through the membrane versus the vapor pressure difference between outside and inside allows a check of the method. Whenever the vapor pressure difference is high, i.e. the air in the air space is humid and the sheathing is dryer, the switchable membrane should be closed (i.e. impermeable) and the resulting moisture flux density should be low. Whenever the vapor pressure in the air layer is lower than the vapor pressure in the sheathing, the membrane should be open (i.e. permeable) to allow diffusion from sheathing to ventilated air space and therefore drying. The moisture flux density through the membrane vs. the vapor pressure difference between outside and inside is shown in Figure 15. The graph shows that the modelled moisture flux approaches the red line, which indicates the expected low moisture flux with a 0.5 -perm membrane when the vapor pressure in the air layer is higher than in the sheathing (positive vapor pressure difference in Figure 15). In contrast, the blue line indicates the expected high moisture flux with a 50-perm membrane when the vapor pressure in the air layer is lower than in the sheathing (negative vapor pressure difference in Figure 15). The graph also shows the cases when the switching as realized in the software only partially works; this is the case when the simulated moisture flux density approaches the green line, which indicates when only one membrane of the two-membrane system is closed and the other one is open. For example, all values close to the green line with negative vapor pressure difference mean, that both, the air layer was below $80 \% \mathrm{RH}$ and the sheathing was below $80 \% \mathrm{RH}$ but with the sheathing more humid than the air layer (assuming the same temperature), which caused one of the two membranes to close (see logic in Section 2.3), leading to a missed opportunity for further drying. Without the limitations of the simulation software, those values could be eliminated, leading to an even better performance of the switchable membrane under real life conditions. The results are therefore considered conservative.

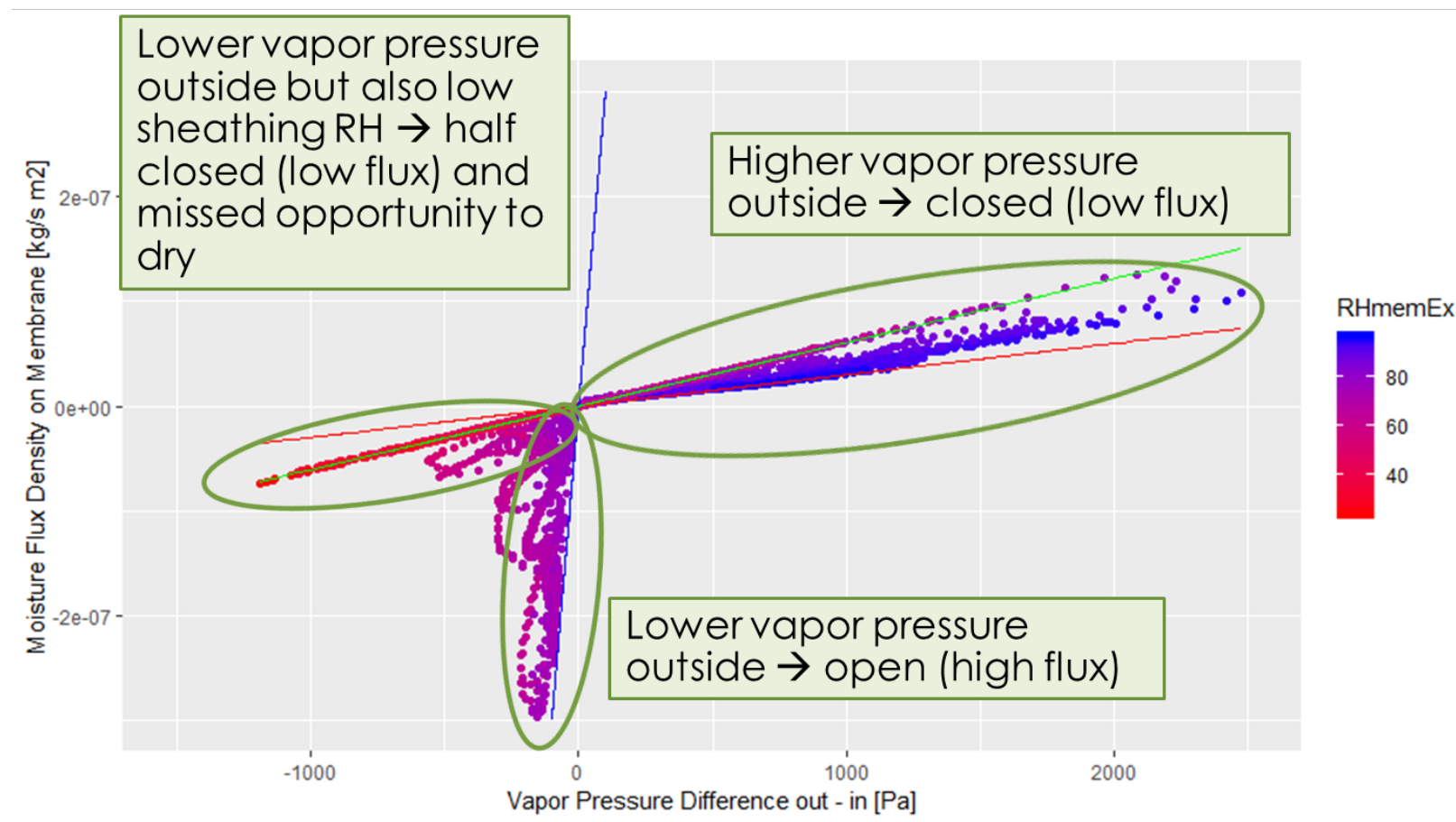

Figure 15: Moisture flux density on membrane versus vapor pressure difference outside-inside for an exemplary case with switchable membrane including explaining remarks. Red line indicates expected moisture flux at 0.5 perm and blue line expected moisture flux at 50 perm. 


\section{RESULTS AND DISCUSSION}

In the following section, result graphs for mold index as well as tables with comparison values for the 21 cases listed in Chapter 3 are presented without further description or assessment. Each subchapter ends with a short discussion of the results.

\subsection{IN-DEPTH ANALYSIS CZ 2 AND 5}

A comparison between wall assemblies with different sheathing materials was conducted for Houston (CZ 2) and Chicago (CZ 5).

\subsubsection{Houston}

The mold index for the wall with OSB sheathing in Houston is shown in Figure 16. No mold growth is found for either case.

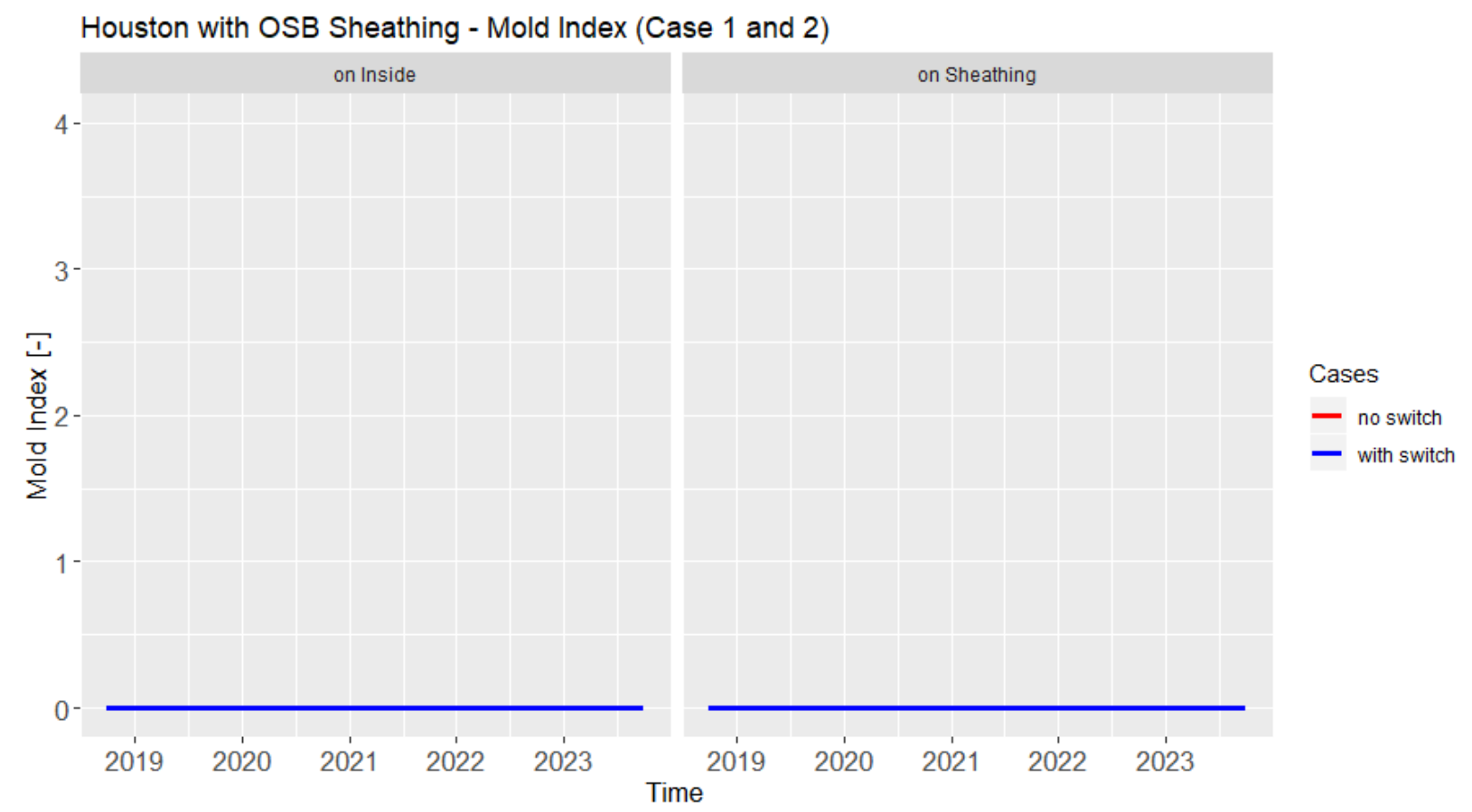

Figure 16: Mold index at the interface between interior gypsum and cavity insulation (inside) and interface between OSB sheathing and cavity insulation (on Sheathing) for the case with static (no switch = red) and with switchable (with switch = blue) membrane in Houston

Table 2 summarizes assessment values for the wall with OSB sheathing in Houston.

Table 2: Assessment values for the comparison between static (no switch) and switchable (with switch) membrane as WRB on OSB sheathing in Houston

\begin{tabular}{|l|l|l|}
\hline & No switch & With switch \\
\hline $\begin{array}{l}\text { Max. MI between OSB } \\
\text { sheathing and cavity } \\
\text { insulation [-] }\end{array}$ & 0.0 & 0.0 \\
\hline
\end{tabular}




\begin{tabular}{|l|l|l|}
\hline $\begin{array}{l}\text { Max. MI between interior } \\
\text { gypsum and cavity insulation } \\
{[-]}\end{array}$ & 0.0 & 0.0 \\
\hline Heating Load $[\mathrm{kWh} / \mathrm{m} 2]$ & -9.45 & -9.45 \\
\hline Cooling Load $[\mathrm{kWh} / \mathrm{m} 2]$ & 7.97 & 7.97 \\
\hline Moisture Load $[\mathrm{g} / \mathrm{m} 2]$ & 593.8 & 702.9 \\
\hline Sheath. mean $\mathrm{MC}[\mathrm{kg} / \mathrm{m} 2]$ & 11.9 & 10.9 \\
\hline Hours above crit. MC [h] & 0 & 0 \\
\hline
\end{tabular}

The mold index for the wall with exterior gypsum sheathing in Houston is shown in Figure 17.

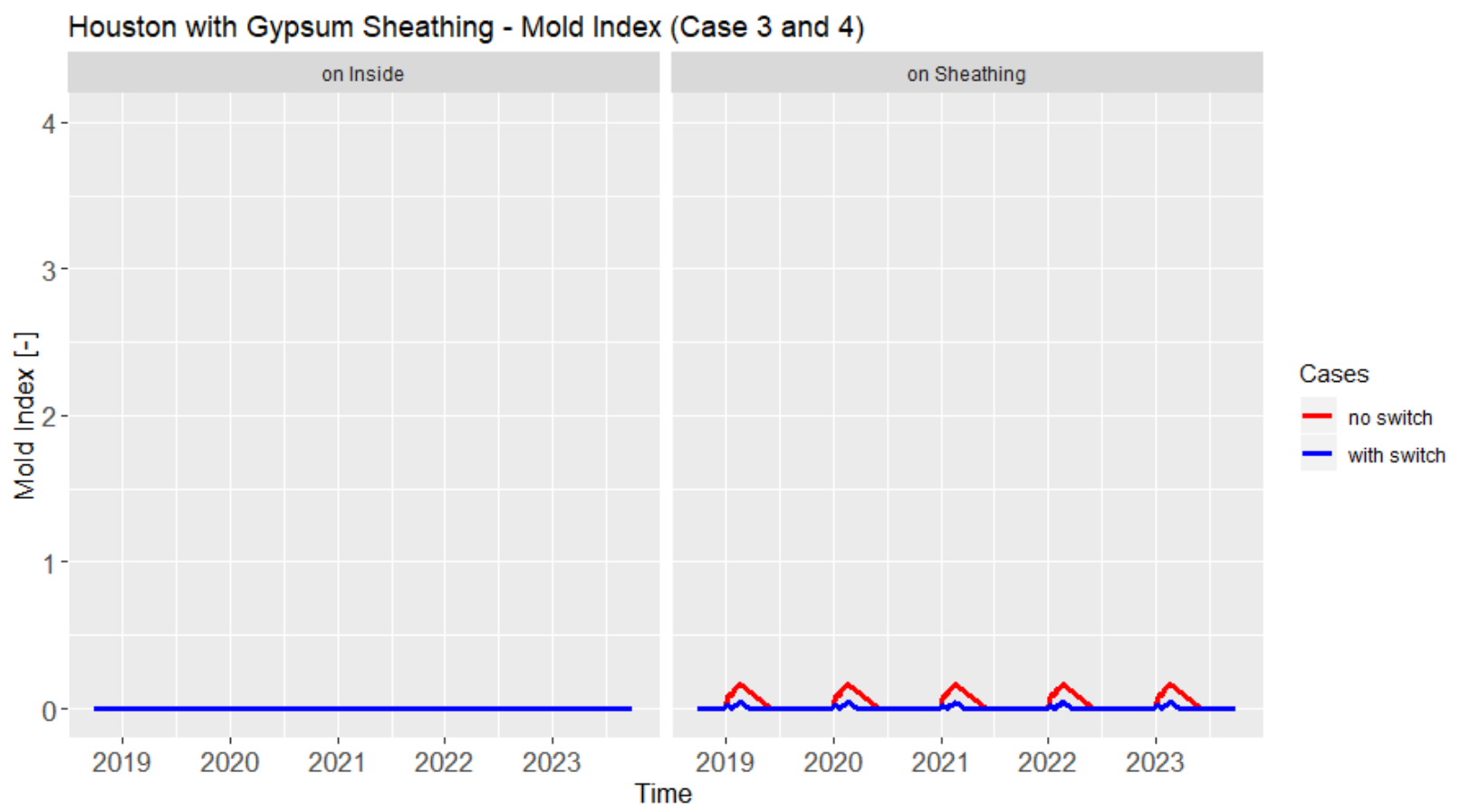

Figure 17: Mold index on interface between interior gypsum and cavity insulation (inside) and interface between exterior gypsum sheathing and cavity insulation (on Sheathing) for the case with static (no switch = red) and with switchable (with switch = blue) membrane in Houston

Table 3 summarizes assessment values for the wall with exterior gypsum sheathing in Houston.

Table 3: Assessment values for the comparison between static (no switch) and switchable (with switch) membrane as WRB on exterior gypsum sheathing in Houston

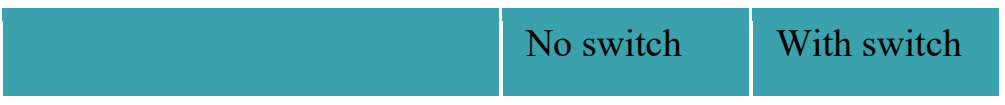




\begin{tabular}{|l|l|l|}
\hline $\begin{array}{l}\text { Max. MI between OSB } \\
\text { sheathing and cavity } \\
\text { insulation [-] }\end{array}$ & 0.16 & 0.05 \\
\hline $\begin{array}{l}\text { Max. MI between interior } \\
\text { gypsum and cavity insulation } \\
{[-]}\end{array}$ & 0.0 & 0.0 \\
\hline Heating Load [kWh/m2] & -9.67 & -9.66 \\
\hline Cooling Load $[\mathrm{kWh} / \mathrm{m} 2]$ & 8.14 & 8.12 \\
\hline Moisture Load [g/m2] & 676.7 & 965.9 \\
\hline Sheath. mean MC [kg/m2] & 3.31 & 3.20 \\
\hline Hours above crit. MC [h] & 458 & 208 \\
\hline
\end{tabular}

\subsubsection{Chicago}

The mold index for the wall with OSB sheathing in Chicago is shown in Figure 18.

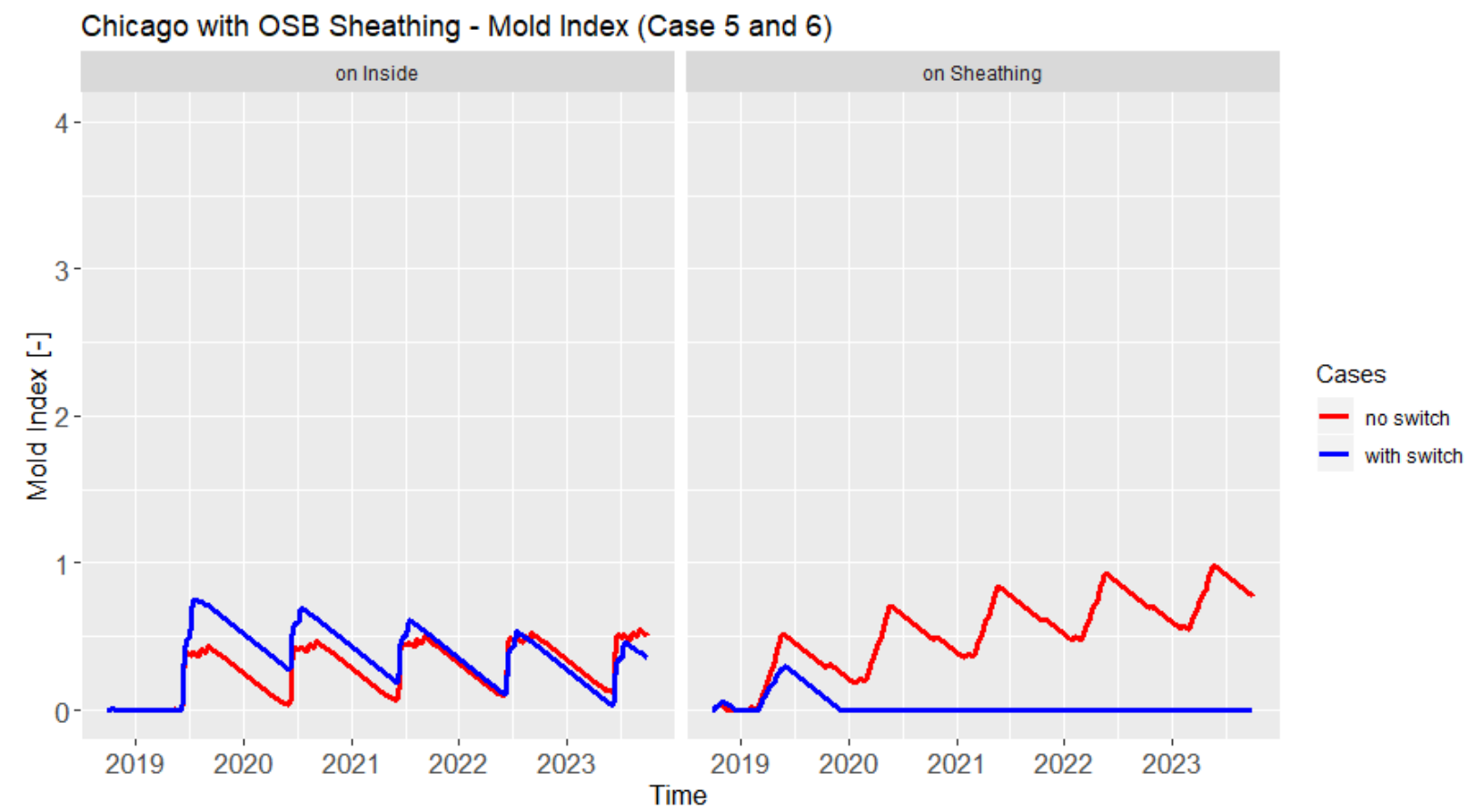

Figure 18: Mold index at the interface between interior gypsum and cavity insulation (inside) and interface between OSB sheathing and cavity insulation (on Sheathing) for the case with static (no switch = red) and with switchable (with switch = blue) membrane in Chicago

Table 4 summarizes assessment values for the wall with OSB sheathing in Chicago. 
Table 4 Assessment values for the comparison between static (no switch) and switchable (with switch) membrane as WRB on OSB sheathing in Chicago

\begin{tabular}{|l|l|l|}
\hline $\begin{array}{l}\text { Max. MI between OSB } \\
\text { sheathing and cavity } \\
\text { insulation [-] }\end{array}$ & 0.93 & 0.0 \\
\hline $\begin{array}{l}\text { Max. MI between interior } \\
\text { gypsum and cavity insulation } \\
{[-]}\end{array}$ & 0.52 & 0.53 \\
\hline Heating Load [kWh/m2] & -20.70 & -20.68 \\
\hline $\begin{array}{l}\text { Cooling Load [kWh/m2] } \\
\text { Moisture Load [g/m2] }\end{array}$ & 2.26 & 2.24 \\
\hline Sheath. mean MC [kg/m2] & 78.8 & 290.5 \\
\hline Hours above crit. MC [h] & 0 & 63.3 \\
\hline
\end{tabular}

The mold index for the wall with exterior gypsum sheathing in Chicago is shown in Figure 19.

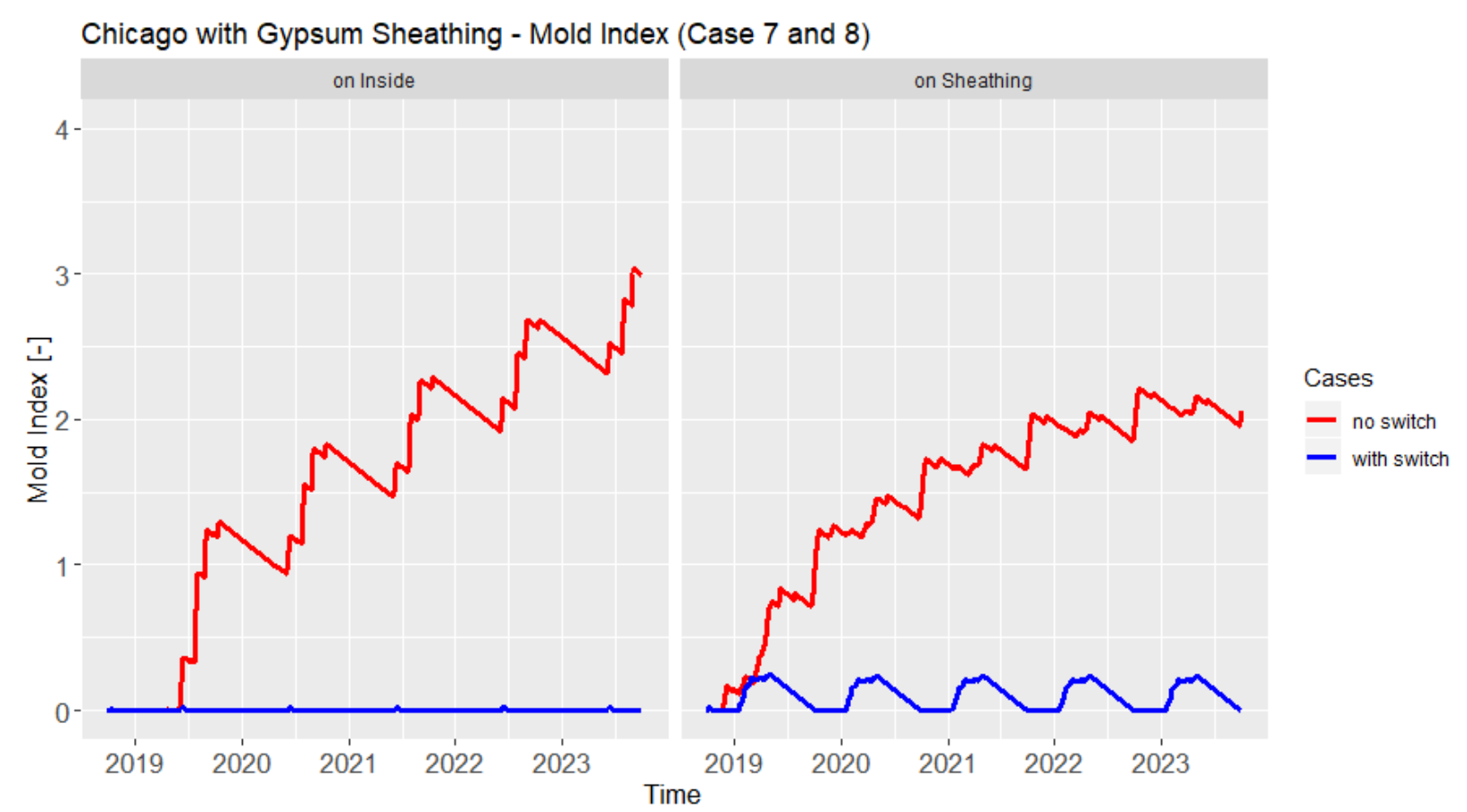

Figure 19: Mold index at the interface between interior gypsum and cavity insulation (inside) and interface between exterior gypsum sheathing and cavity insulation (on Sheathing) for the case with static (no switch = red) and with switchable (with switch = blue) membrane in Chicago

Table 5 summarizes assessment values for the wall with exterior gypsum sheathing in Chicago. 
Table 5: Assessment values for the comparison between static (no switch) and switchable (with switch) membrane as WRB on exterior gypsum sheathing in Chicago

\begin{tabular}{|l|l|l|}
\hline & No switch & With switch \\
\hline $\begin{array}{l}\text { Max. MI between OSB } \\
\text { sheathing and cavity } \\
\text { insulation [-] }\end{array}$ & 2.21 & 0.23 \\
\hline $\begin{array}{l}\text { Max. MI between interior } \\
\text { gypsum and cavity insulation } \\
{[-]}\end{array}$ & 2.69 & 0.02 \\
\hline Heating Load [kWh/m2] & -21.03 & -21.00 \\
\hline Cooling Load [kWh/m2] & 2.37 & 2.29 \\
\hline Moisture Load [g/m2] & 346.1 & 198.3 \\
\hline Sheath. mean MC [kg/m2] & 7.0 & 5.7 \\
\hline Hours above crit. MC [h] & 4285 & 2015 \\
\hline
\end{tabular}

\subsubsection{Discussion on Baseline Simulations and Construction Types}

In CZ 2A, the outdoor vapor pressure is so high most of the time, that an impermeable WRB, which was used for the baseline case, is sufficient. That means that most of the time the outdoor relative humidity is higher than the relative humidity in the sheathing; thus, the switch of the membrane is rarely activated, and the membrane remained at its high permeability state. Therefore, the proposed wall section performs well with the static WRB and no moisture issues are expected.

In CZ 5A, the OSB slows down the vapor diffusion. This can lead to higher RH at the interface between the insulation and the OSB sheathing due to water vapor diffusion from indoors during the winter. It also reduces the drying capacity of the cavity. However, after rain events the cavity is loaded way slower, which leads to overall lower moisture conditions.

In summary it is found that the application of a switchable WRB reduces the vapor drive into the wall cavity when the relative humidity is high outdoors. It therefore reduces the mold growth risk significantly. The riskier system seems to be the one with exterior gypsum board. Further assessments are therefore based solely on this system.

\subsection{CLIMATE ZONE COMPARISON}

\subsubsection{Atlanta}

The mold index for the wall with exterior gypsum sheathing in Atlanta is shown in Figure 20. 


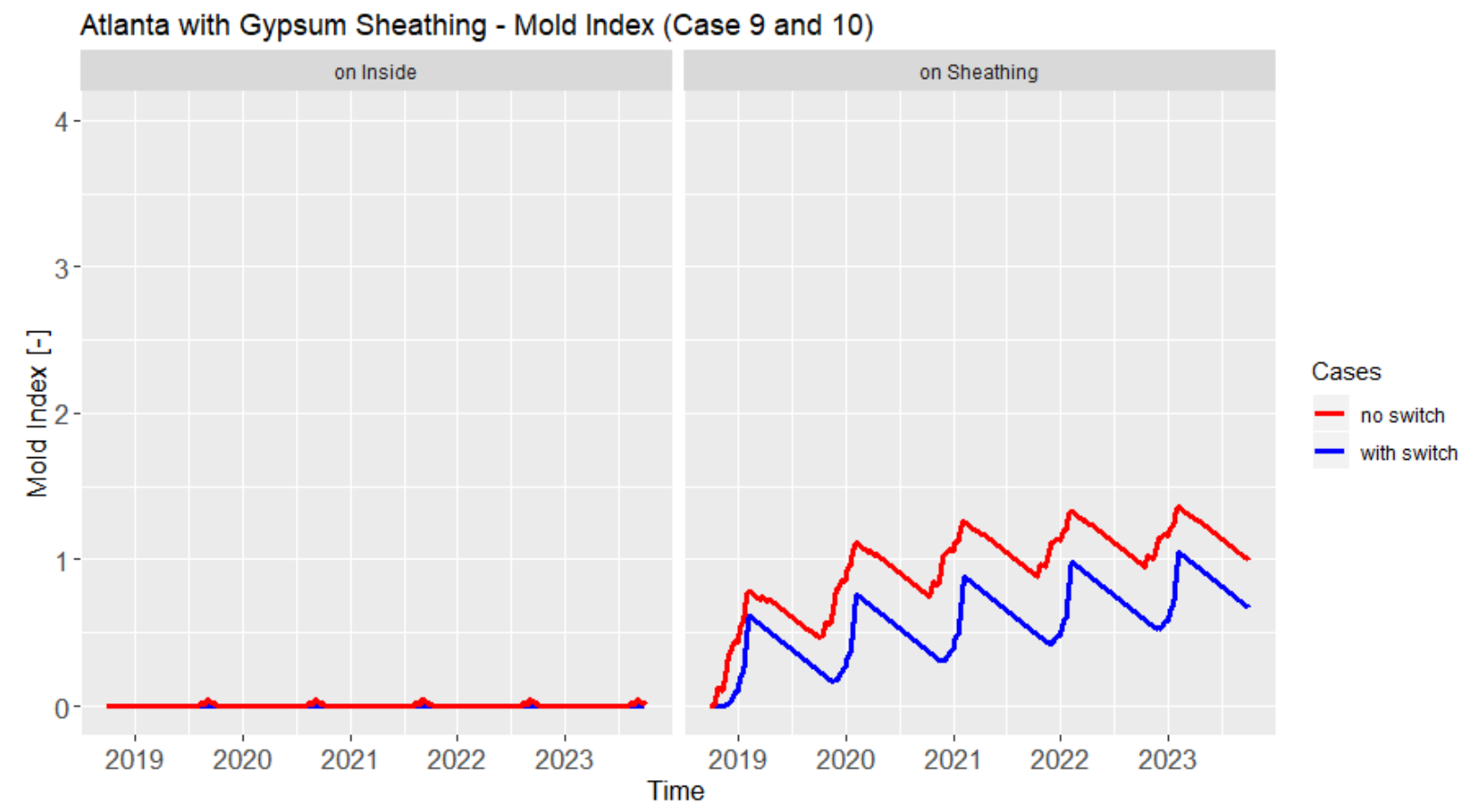

Figure 20: Mold index at the interface between interior gypsum and cavity insulation (inside) and interface between exterior gypsum sheathing and cavity insulation (on Sheathing) for the case with static (no switch = red) and with switchable (with switch = blue) membrane in Atlanta

Table 6 summarizes assessment values for the wall with exterior gypsum sheathing in Atlanta.

Table 6: Assessment values for the comparison between static (no switch) and switchable (with switch) membrane as WRB on exterior gypsum sheathing in Atlanta

\begin{tabular}{|l|l|l|}
\hline & No switch & With switch \\
\hline $\begin{array}{l}\text { Max. MI between OSB } \\
\text { sheathing and cavity } \\
\text { insulation [-] }\end{array}$ & 1.33 & 0.98 \\
\hline $\begin{array}{l}\text { Max. MI between interior } \\
\text { gypsum and cavity insulation } \\
{[-]}\end{array}$ & 0.05 & 0 \\
\hline $\begin{array}{l}\text { Heating Load [kWh/m2] } \\
\text { Cooling Load [kWh/m2] }\end{array}$ & -12.60 & -12.54 \\
\hline Moisture Load [g/m2] & 2192.5 & 3.78 \\
\hline Sheath. mean MC [kg/m2] & 5.20 & 530.1 \\
\hline Hours above crit. MC [h] & 2058 & 1362 \\
\hline
\end{tabular}




\subsubsection{Baltimore}

The mold index for the wall with exterior gypsum sheathing in Baltimore is shown in Figure 21.

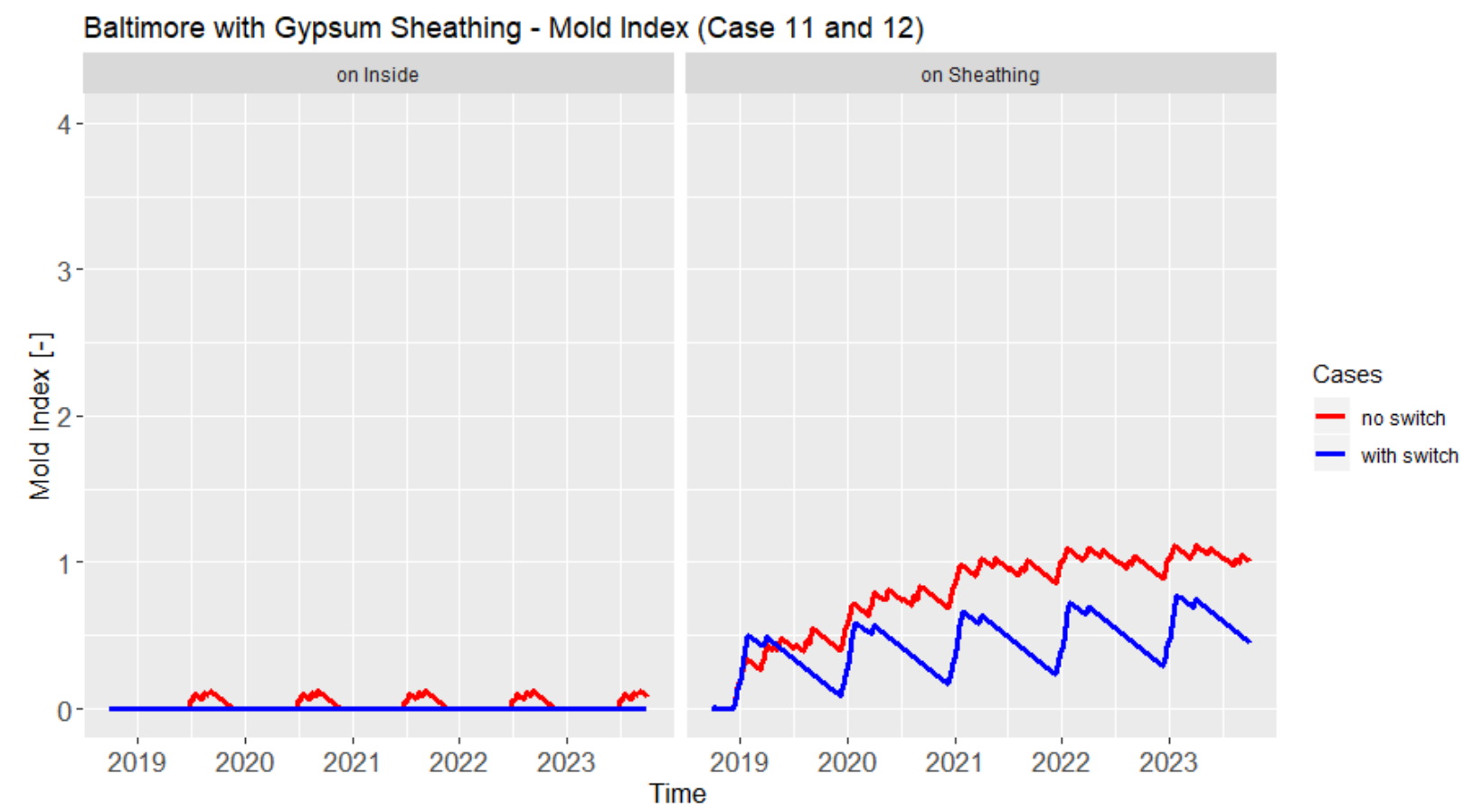

Figure 21: Mold index at the interface between interior gypsum and cavity insulation (inside) and interface between exterior gypsum sheathing and cavity insulation (on Sheathing) for the case with static (no switch = red) and with switchable (with switch = blue) membrane in Baltimore

Table 7 summarizes assessment values for the wall with exterior gypsum sheathing in Baltimore.

Table 7: Assessment values for the comparison between static (no switch) and switchable (with switch) membrane as WRB on exterior gypsum sheathing in Baltimore

\begin{tabular}{|l|l|l|}
\hline $\begin{array}{l}\text { Max. MI between OSB } \\
\text { sheathing and cavity } \\
\text { insulation [-] }\end{array}$ & 1.10 & 0.72 \\
\hline $\begin{array}{l}\text { Max. MI between interior } \\
\text { gypsum and cavity insulation } \\
\text { [-] }\end{array}$ & 0.12 & 0 \\
\hline $\begin{array}{l}\text { Heating Load }[\mathrm{kWh} / \mathrm{m} 2] \\
\text { Cooling Load [kWh/m2] }\end{array}$ & -18.06 & -18.01 \\
\hline Moisture Load [g/m2] & 1.86 & 1.85 \\
\hline Sheath. mean $\mathrm{MC}[\mathrm{kg} / \mathrm{m} 2]$ & 5.20 & 359.6 \\
\hline
\end{tabular}




\begin{tabular}{|l|l|l|} 
Hours above crit. MC [h] & 2039 & 1417
\end{tabular}

\subsubsection{Seattle}

The mold index for the wall with exterior gypsum sheathing in Seattle is shown in Figure 22.

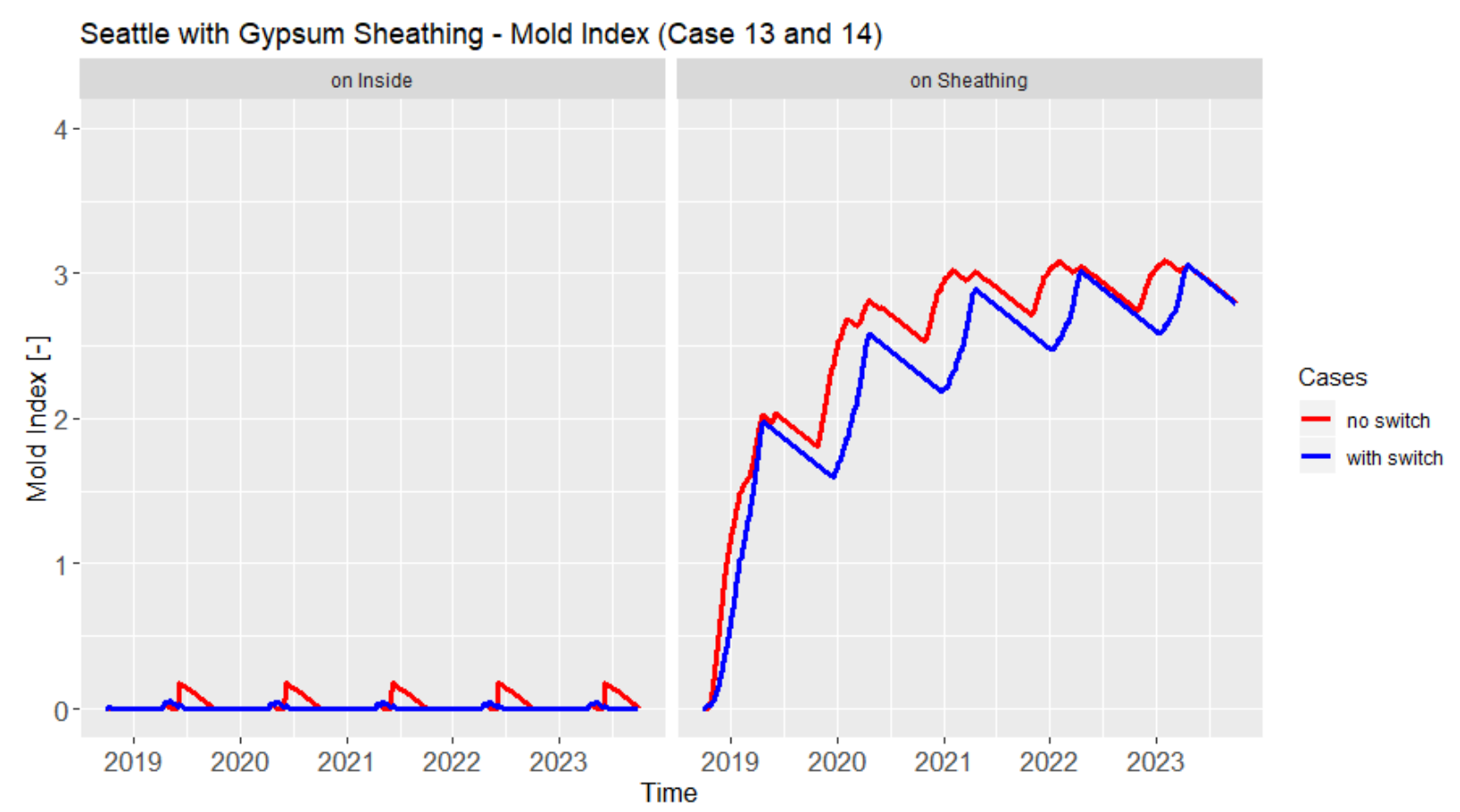

Figure 22: Mold index at the interface between interior gypsum and cavity insulation (inside) and interface between exterior gypsum sheathing and cavity insulation (on Sheathing) for the case with static (no switch = red) and with switchable (with switch = blue) membrane in Seattle

Table 8 summarizes assessment values for the wall with exterior gypsum sheathing in Seattle.

Table 8: Assessment values for the comparison between static (no switch) and switchable (with switch) membrane as WRB on exterior gypsum sheathing in Seattle

\begin{tabular}{|l|l|l|}
\hline & No switch & With switch \\
\hline $\begin{array}{l}\text { Max. MI between OSB } \\
\text { sheathing and cavity } \\
\text { insulation [-] }\end{array}$ & 3.08 & 3.01 \\
\hline $\begin{array}{l}\text { Max. MI between interior } \\
\text { gypsum and cavity insulation } \\
{[-]}\end{array}$ & 0.18 & 0.05 \\
\hline $\begin{array}{l}\text { Heating Load [kWh/m2] } \\
\text { Cooling Load [kWh/m2] }\end{array}$ & -17.39 & -17.43 \\
\hline Moisture Load [g/m2] & 0.14 & 0.17 \\
\hline
\end{tabular}




\begin{tabular}{|l|l|l|}
\hline Sheath. mean MC [kg/m2] & 8.13 & 7.11 \\
\hline Hours above crit. MC [h] & 4539 & 3503 \\
\hline
\end{tabular}

\subsubsection{Discussion on Climate Zones}

The results show that a switchable WRB reduces mold growth risk and average sheathing moisture content in all climate zones. An assembly with obvious moisture related problems in a certain location (Seattle) does not necessarily work with a switchable membrane because... The modelled performance could be improved with better control of the switching point. This would require either a switching point based on location (i.e. climatic conditions) or switching of the membrane based on actual conditions of the layers of the building assembly (i.e. measuring vapor pressure difference across membrane).

The switchable WRB has almost no effect on the sensible load in any of the evaluated climate zones; that is, the wall with static WRB shows a similar heat flux density as the wall with switchable membrane. The latent load can vary significantly between the static and the switchable WRB but it is negligible compared to the latent loads that originate from ventilation and indoors.

\subsection{IMPACT OF BULK WATER LEAKAGE}

Due to workmanship or detailing, there are often leaks in building components. This can be modelled in WUFI ${ }^{~}$ by adding a moisture source to a layer in the component. To determine if the switchable membrane shows additional benefits by enabling drying of moisture accumulation due to leakage, a moisture source was added that deposited $1 \%$ of the driving rain into the component in the outer part of the sheathing.

\subsubsection{Bulk water leakage results}

The mold index for the wall with exterior gypsum sheathing and $1 \%$ bulk water entry in Chicago is shown in Figure 23 for a baseline case with static WRB and two cases with switchable membrane, one with a 50 perm maximum and one with a 5 perm maximum. 


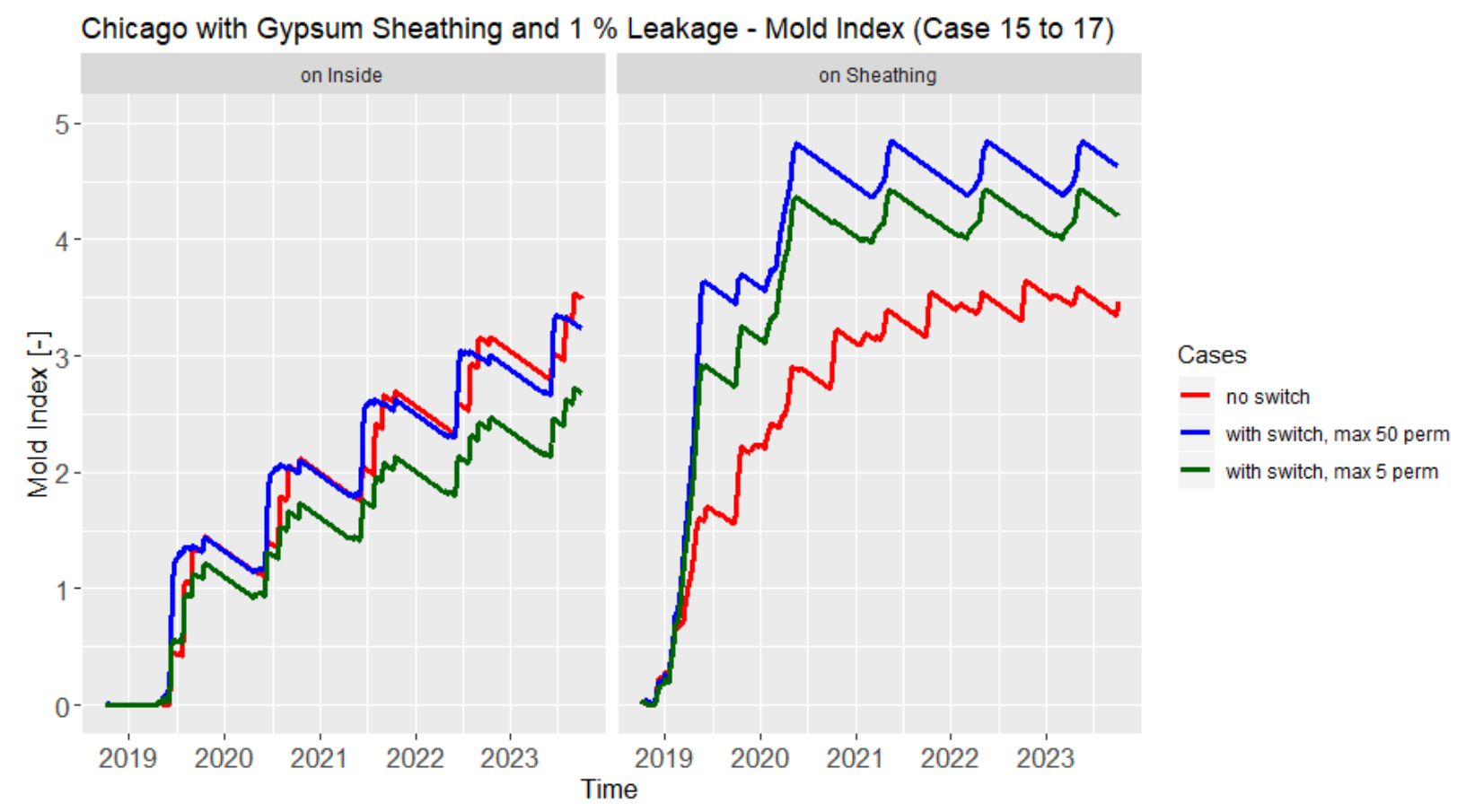

Figure 23: Mold index at the interface between interior gypsum and cavity insulation (inside) and interface between exterior gypsum sheathing and cavity insulation (on Sheathing) for the case with static (no switch = red) and with switchable membrane with maximum 50 perm (blue) or 5 perm (green) in an assembly where 1\% of the driving rain leaks onto the WRB in Chicago

Table 9 summarizes assessment values for the wall with 1\% rain penetration and with exterior gypsum sheathing in Chicago with two different maximum permeabilities.

Table 9: Assessment values for the comparison between static (no switch) and switchable (with switch) membrane with maximum 50 perm and 5 perm as WRB on exterior gypsum sheathing in Chicago with 1\% leakage of driving rain deposited on the sheathing

\begin{tabular}{|l|l|l|l|}
\hline & No switch & $\begin{array}{l}\text { Switch 50 } \\
\text { perm }\end{array}$ & $\begin{array}{l}\text { Switch 5 } \\
\text { perm }\end{array}$ \\
\hline $\begin{array}{l}\text { Max. MI between OSB } \\
\text { sheathing and cavity } \\
\text { insulation [-] }\end{array}$ & 3.64 & 4.84 & 4.42 \\
\hline $\begin{array}{l}\text { Max. MI between interior } \\
\text { gypsum and cavity insulation } \\
{[-]}\end{array}$ & 3.16 & 3.04 & 2.47 \\
\hline $\begin{array}{l}\text { Heating Load [kWh/m2] } \\
\text { Cooling Load [kWh/m2] }\end{array}$ & -21.09 & -21.07 & -21.13 \\
\hline Moisture Load [g/m2] & 357.5 & 2.29 & 2.34 \\
\hline Sheath. mean MC [kg/m2] & 10.41 & 389.5 & 353.3 \\
\hline Hours above crit. MC [h] & 4960 & 5388 & 17.42 \\
\hline
\end{tabular}




\subsubsection{Discussion bulk water leakage}

When water leakage from driving rain occurs, high air layer RH and sheathing RH coincide. Therefore, the switchable membrane remains impermeable (closed) and the switchable membrane did not have a significant impact. However, the implemented switch control of the membrane prevents additional drying of the sheathing once the sheathing RH is below $80 \%$. This could be improved with control based on vapor pressure difference in a real-life application.

The energy impact (sensible loads) is still minimal, even with the high moisture content at the sheathing/insulation layer.

\subsection{IMPACT OF PERMEANCE OPTIONS AND SWITCHING POINTS FOR SWITCHABLE MEMBRANES}

\subsubsection{Switching point results}

The mold index for the wall with exterior gypsum sheathing and three different switching point relative humidity values (i.e., 80\%, 65\%, and 50\%) in Chicago are shown in Figure 24.

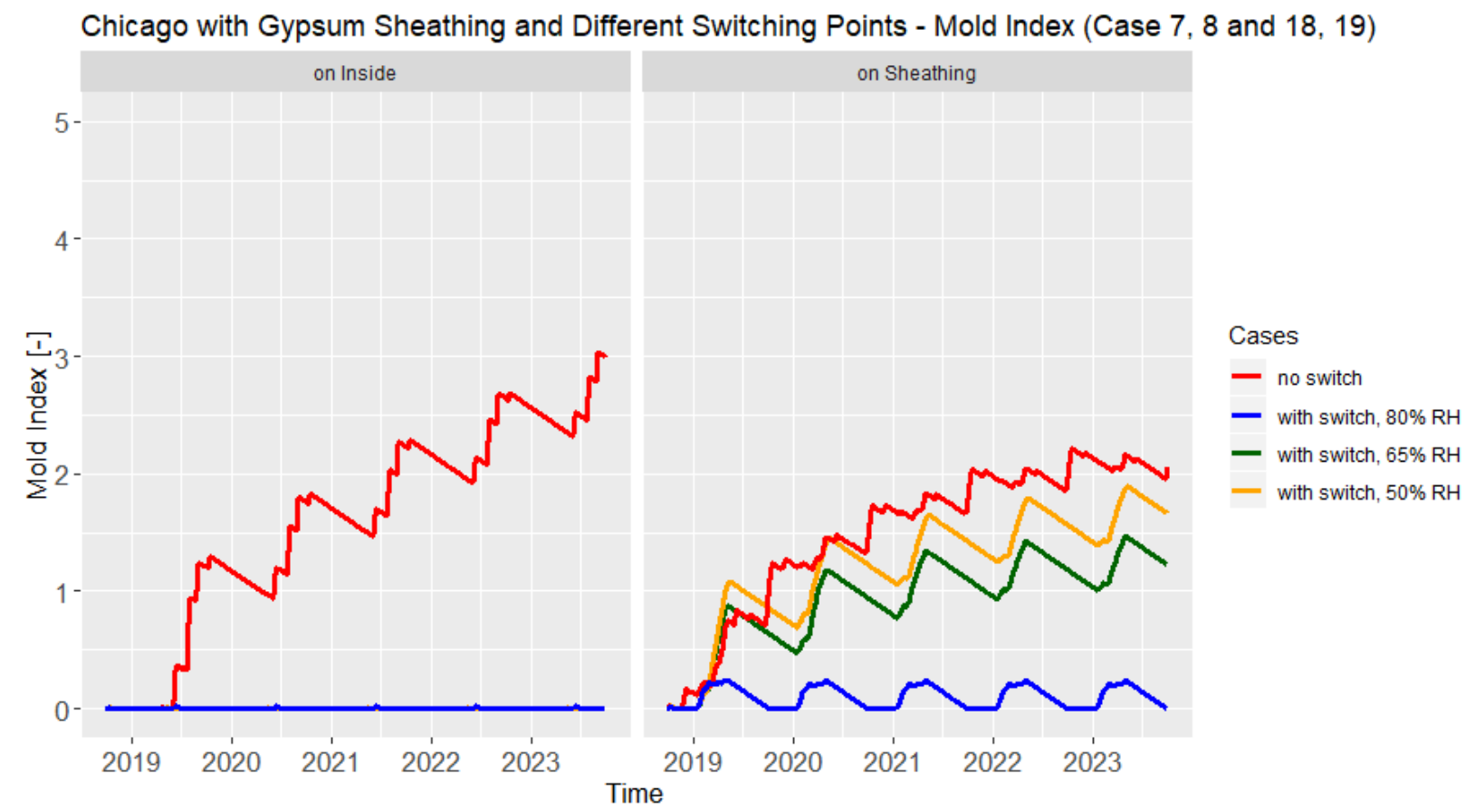

Figure 24: Mold index at the interface between interior gypsum and cavity insulation (inside) and interface between exterior gypsum sheathing and cavity insulation (on Sheathing) for the case with static (no switch = red) and with switchable membrane with switching at relative humidity of 50\% (orange), 65\% (green) and $80 \%$ (blue) in Chicago

Table 10 summarizes assessment values for the wall with exterior gypsum sheathing in Chicago for three different switching point relative humidity values. 
Table 10: Assessment values for the comparison between static (no switch) and switchable (with switch) membrane as WRB with switching points at 50\%, 65\% and $80 \%$ RH on exterior gypsum sheathing in Chicago

\begin{tabular}{|l|l|l|l|l|}
\hline & No switch & Switch $80 \%$ & Switch 65\% & Switch 50\% \\
\hline $\begin{array}{l}\text { Max. MI between OSB } \\
\text { sheathing and cavity } \\
\text { insulation [-] }\end{array}$ & 2.21 & 0.23 & 1.42 & 1.79 \\
\hline $\begin{array}{l}\text { Max. MI between interior } \\
\text { gypsum and cavity insulation } \\
{[-]}\end{array}$ & 2.69 & 0.02 & 0.02 & 0.01 \\
\hline $\begin{array}{l}\text { Heating Load [kWh/m2] } \\
\text { Cooling Load [kWh/m2] }\end{array}$ & -21.03 & -21.00 & -21.01 & -21.01 \\
\hline Moisture Load [g/m2] & 2.37 & 2.29 & 2.30 & 2.30 \\
\hline Sheath. mean MC [kg/m2] & 7.0 & 198.3 & 191.9 & 190.0 \\
\hline Hours above crit. MC [h] & 4285 & 5.7 & 6.0 & 6.4 \\
\hline
\end{tabular}

\subsubsection{Switching perm results}

The mold index for the wall with exterior gypsum sheathing and three different maximum permeance values (i.e., 50, 20 and 5 perms) in Chicago are shown in Figure 25.

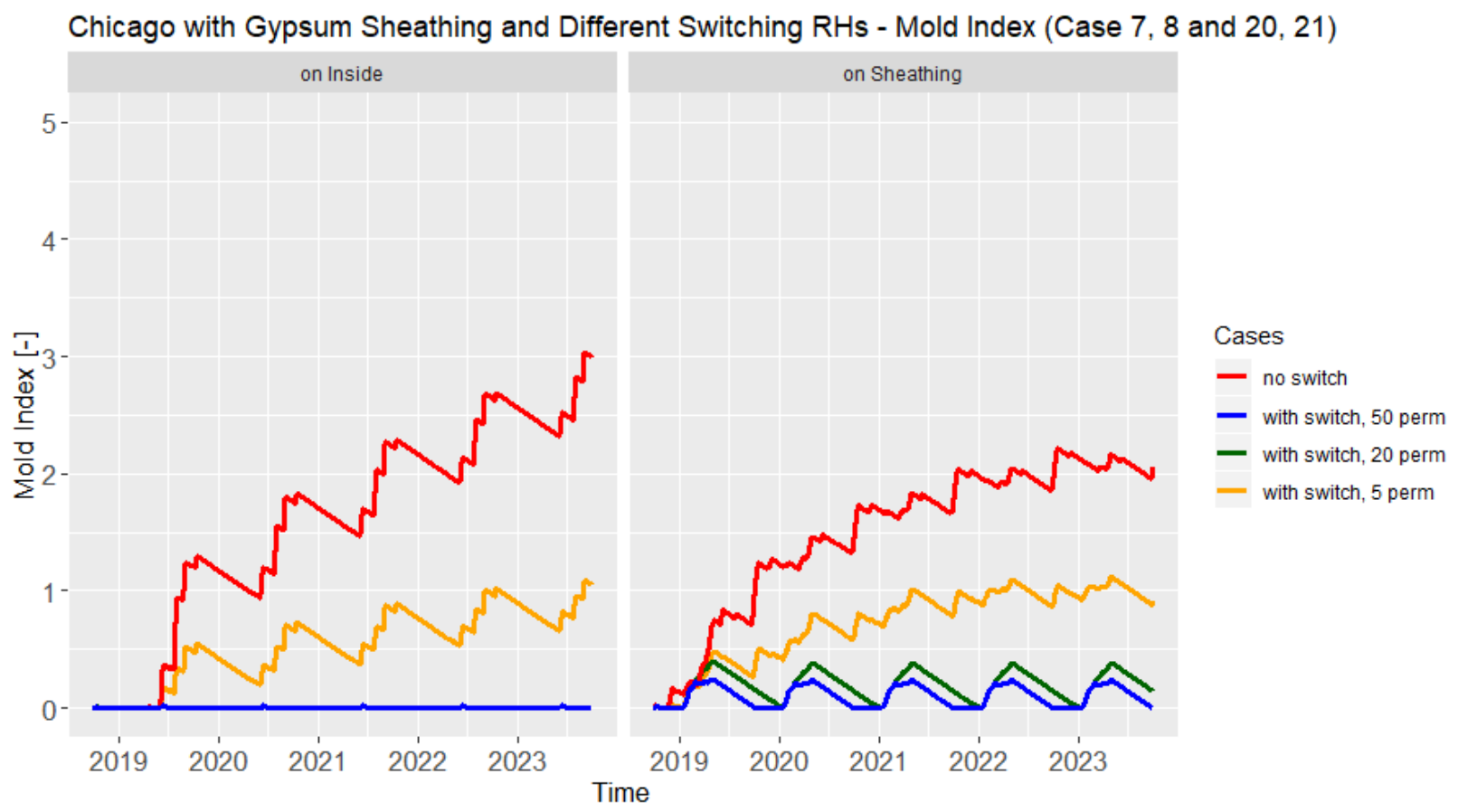


Figure 25: Mold index at the interface between interior gypsum and cavity insulation (inside) and interface between exterior gypsum sheathing and cavity insulation (on Sheathing) for the case with static (no switch = red) and with switchable membrane with maximum permeance of 5 perm (orange), 20 perm (green) and 50 perm (blue) in Chicago

Table 11 summarizes assessment values for the wall with exterior gypsum sheathing in Chicago for three different switching permeance values.

Table 11: Assessment values for the comparison between static (no switch) and switchable (with switch) membrane as WRB with maximum permeance values at 5 perm, 20 perm and 50 perm on exterior gypsum sheathing in Chicago

\begin{tabular}{|l|l|l|l|l|}
\hline & No switch & $\begin{array}{l}\text { Switch 50 } \\
\text { perm }\end{array}$ & $\begin{array}{l}\text { Switch 20 } \\
\text { perm }\end{array}$ & $\begin{array}{l}\text { Switch 5 } \\
\text { perm }\end{array}$ \\
\hline $\begin{array}{l}\text { Max. MI between OSB } \\
\text { sheathing and cavity } \\
\text { insulation [-] }\end{array}$ & 2.21 & 0.23 & 0.38 & 1.09 \\
\hline $\begin{array}{l}\text { Max. MI between interior } \\
\text { gypsum and cavity insulation } \\
{[-]}\end{array}$ & 2.69 & 0.02 & 0.02 & 1.01 \\
\hline $\begin{array}{l}\text { Heating Load [kWh/m2] } \\
\text { Cooling Load [kWh/m2] }\end{array}$ & -21.03 & -21.00 & -21.02 & -21.00 \\
\hline Moisture Load [g/m2] & 346.1 & 2.29 & 2.29 & 2.34 \\
\hline Sheath. mean MC [kg/m2] & 7.0 & 198.3 & 198.0 & 306.2 \\
\hline Hours above crit. MC [h] & 4285 & 5.7 & 5.9 & 6.5 \\
\hline
\end{tabular}

\subsubsection{Discussion on the impact of switching maximum permeance and switching point}

With a lower switching point, drying towards the outside starts later after the sheathing has gained more moisture during winter month. This results in longer periods with higher $\mathrm{RH} / \mathrm{MC}$ in the sheathing and a higher mold growth risk. The results indicate that there is an optimum switching point for every climate zone (if switching is controlled by RH of the sheathing and not by the vapor pressure difference between the sheathing and the ventilated air space). The 50 perm and 20 perm maximum permeance values for the membrane behave almost similarly. The WRB with switch of maximum 20 perm accumulates more moisture in the winter as it is less permeable with temperature dependent vapor drive. It dries out in a way that the mold index for the simulated case does not accumulate. The WRB with switch of maximum 5 perm is too impermeable to allow the cavity to dry out the combined moisture load due to diffusion from indoor sources during the winter and solar driving moisture from outdoors during the summer. This results in moderate mold growth at the sheathing/insulation and insulation/vapor retarder interfaces.

\section{SUMMARY AND CONCLUSIONS}

This study evaluated the effect of a water-resistive barrier (i.e. exterior of the exterior sheathing material in a wood frame wall where it may also be exposed to liquid water) membrane that can switch its water vapor permeability on moisture conditions, mold growth potential and energy demand. Modelling the 
functionality of the switchable membrane is not possible in a direct way with the selected simulation model WUFI ${ }^{\circledR}$ (and no other commercially available hygrothermal component simulation model).

Therefore, some workarounds were developed that allowed modelling the switchable membrane with a conservative approach. Switching the membrane properties means introducing a step change in the simulation model that can result in numerical stability issues. This was successfully resolved by using an adaptive time-step control. The control of the switch is implemented by changing material properties at a certain relative humidity and a two-layer approach to model the membrane. As a consequence, a fully open state of the membrane is not always modeled whenever it would be beneficial for drying which leads to conservative simulation results. A switch that is controlled by vapor pressure difference would improve the performance and be a less conservative approach for the simulation but cannot be implemented in the current version of WUFI Pro.

The simulation study shows that the switchable membrane can reduce the water content in the sheathing and reduce the mold growth risk in the cavity in all climate zones. The effect of the switchable membrane on energy use is small. The differences in sensible losses/gains in heating/cooling period are very small even in cases with a high moisture level. Significant differences in latent gains during cooling period were observed, but those were orders of magnitudes lower than moisture loads from ventilation and interior loads.

The ideal switching point is climate dependent. The switching should be initiated by measured vapor pressure difference across the membrane for practical applications. The maximum (i.e. 50 perm) and minimum (i.e. 0.5 perm) permeance values appear to be the only necessary switching permeances, intermediate states are not required to achieve full performance of the membrane. The acceptable range for the maximum permeance is expected to be climate dependent. One example case was computed and still shows good performance in climate zone $5 \mathrm{~A}$ with a maximum permeance of 20 perm.

Further benefits during the presence of additional moisture sources in the cavity were not observed. With a moisture source based on driving rain, high moisture levels inside and outside of the WRB occur at the same time. The switching point needs to be higher than $80 \%$ when the sheathing has high RH. With a control that is based on vapor pressure difference and moisture sources independent from driving rain a more beneficial behavior is expected. The same applies to constructions that show high moisture levels due to insufficient design that leads to moisture problems as in those cases the full potential of the switchable membrane is utilized.

\section{REFERENCES}

[1] ASHRAE, 2016. "Criteria for Moisture Control Design Analysis in Buildings.” ASHRAE Standard 160.

[2] Salonvaara, Mikael. "Environmental weather loads for hygrothermal analysis and design of buildings." Report RP-1325. ASHRAE, Atlanta (2011).

[3] International Code Council. International energy conservation code 2015. International Code Council, Inc, Washington, D.C. (2015).

[4] Viitanen, Hannu, Vinha, Juha, Salminen, Kati, Ojanen, Tuomo, Peuhkuri, Ruut, Paajanen, Leena, and Lähdesmäki, Kimmo. "Moisture and Bio-deterioration Risk of Building Materials and Structures." Journal of Building Physics Vol. 33 No. 3 (2010): pp. 201-224. DOI $10.1177 / 1744259109343511$. 
APPENDIX A. Weather Data 


\section{$\underline{\text { Houston }}$}
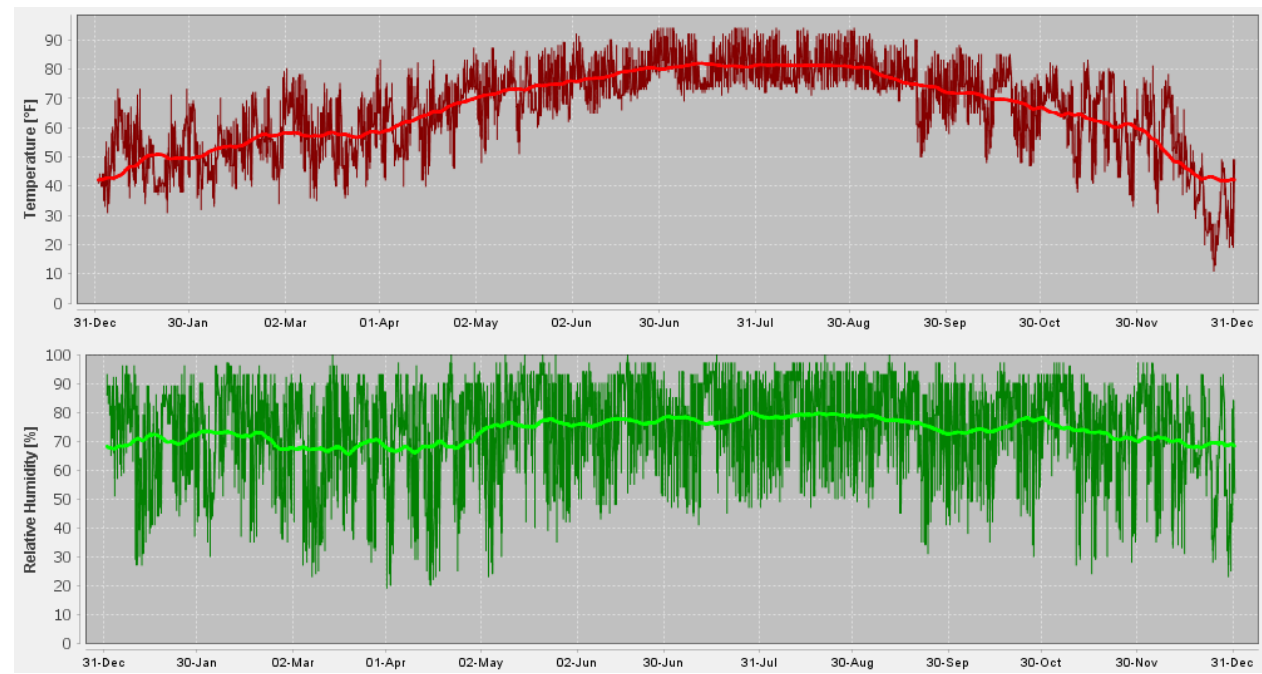

Figure 26: Exterior Temperature and relative humidity from climate file for Houston

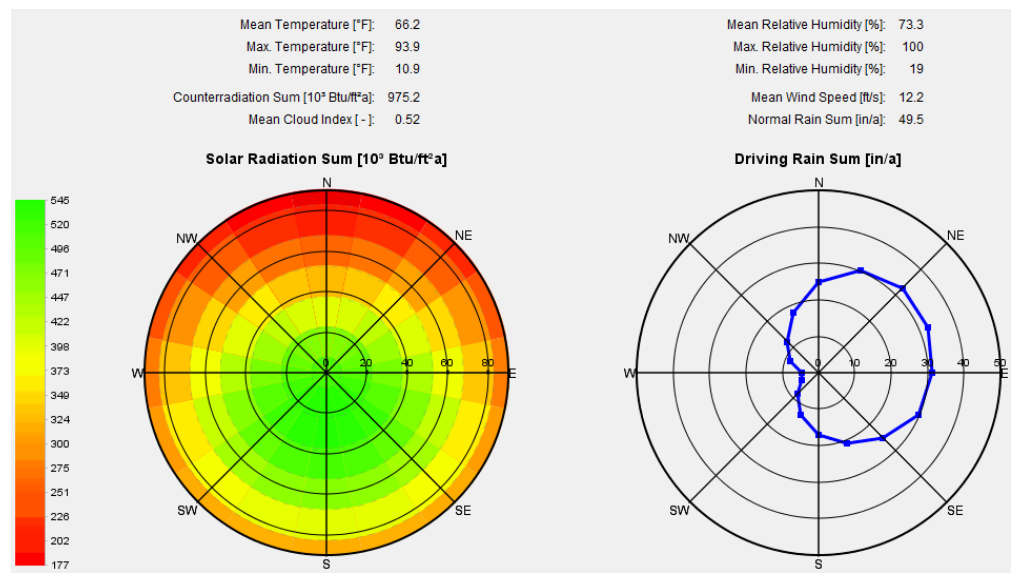

Figure 27: Solar and wind driven rain exposure from climate file for Houston

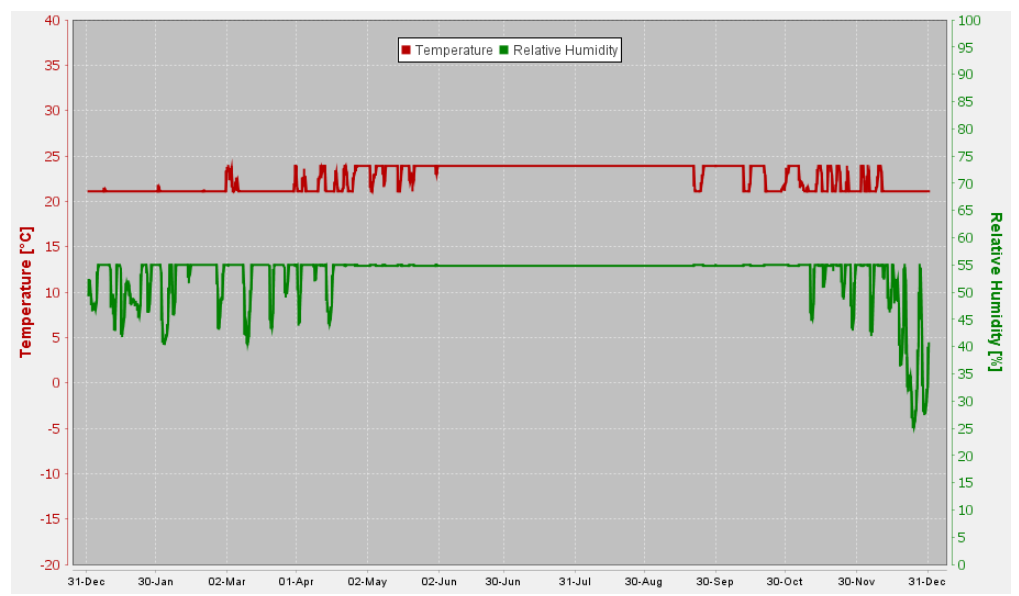

Figure 28: Indoor temperature and relative humidity for Houston 


\section{Chicago}
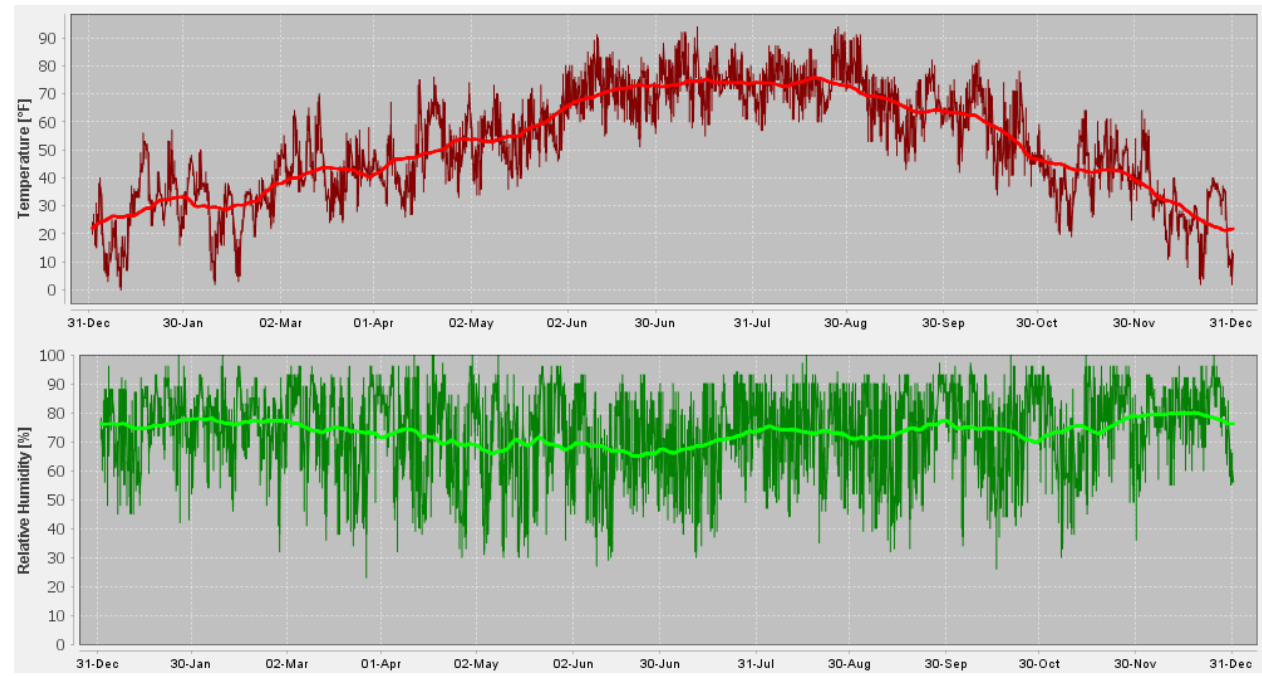

Figure 29: Exterior Temperature and relative humidity from climate file for Chicago

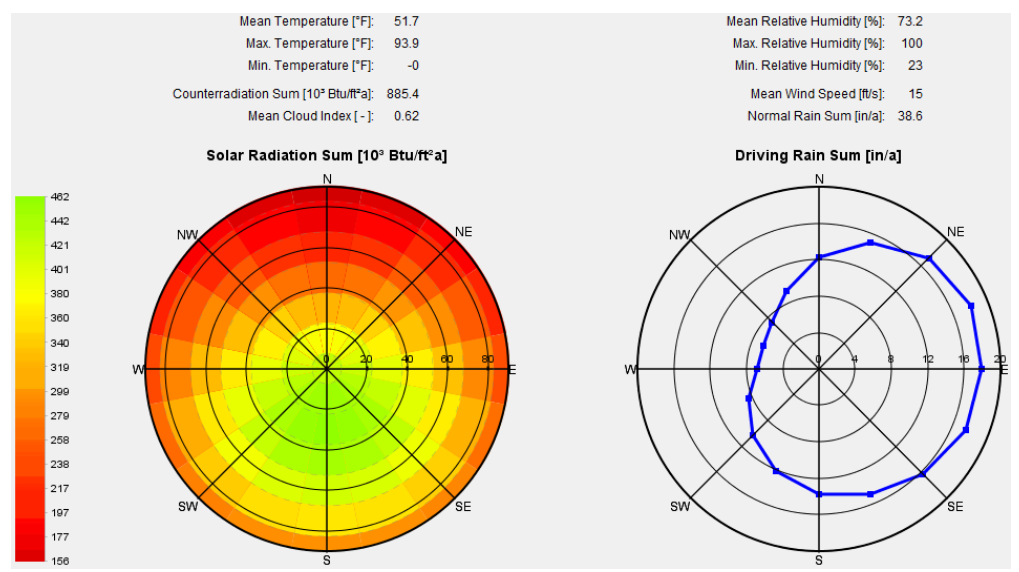

Figure 30: Solar and wind driven rain exposure from climate file for Chicago

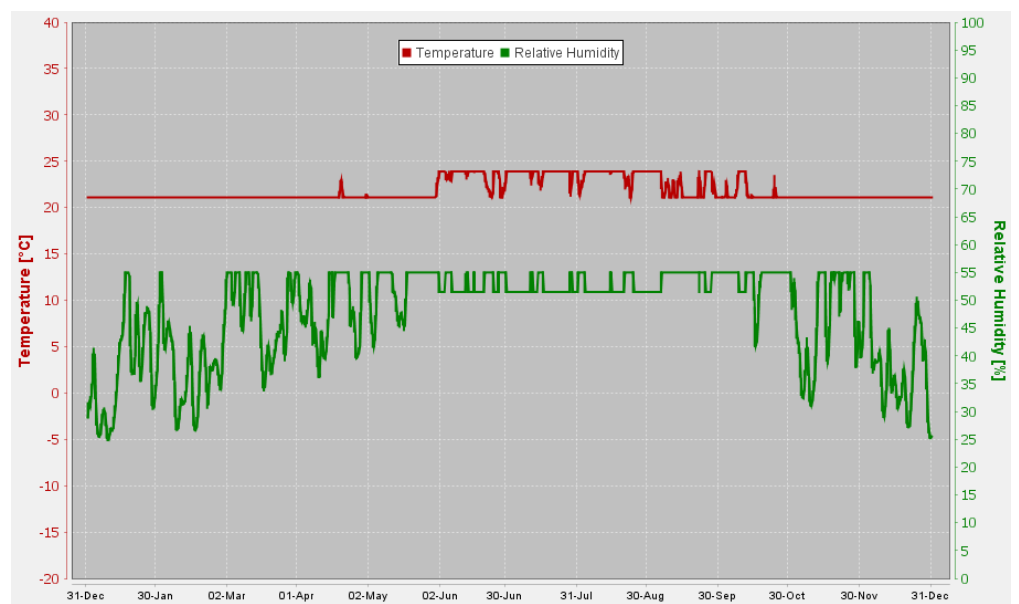

Figure 31: Indoor temperature and relative humidity for Chicago 


\section{Atlanta}
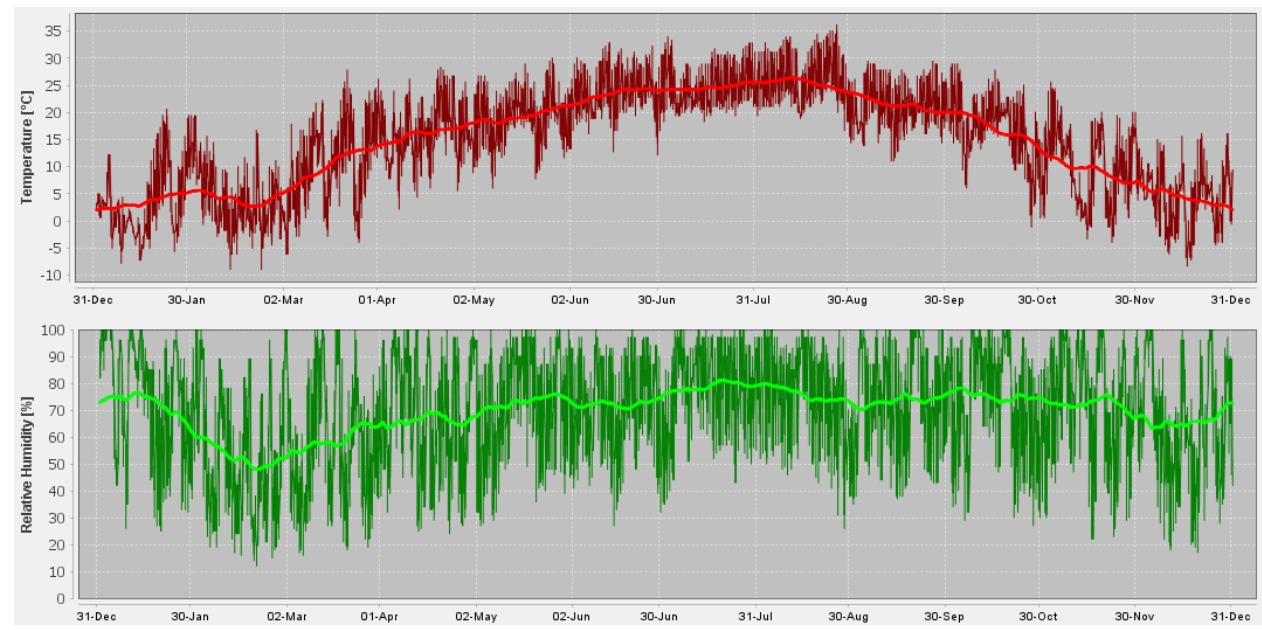

Figure 32: Exterior Temperature and relative humidity from climate file for Atlanta
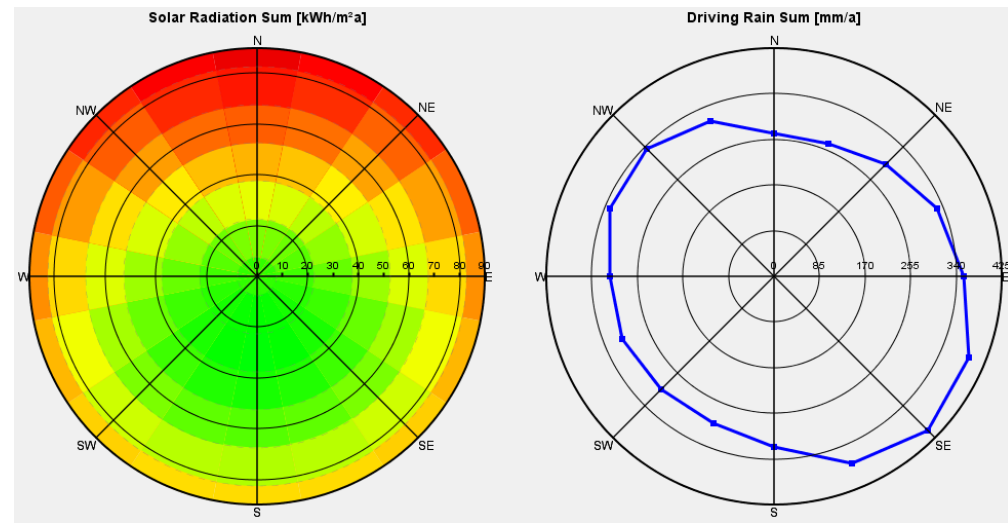

Figure 33: Solar and wind driven rain exposure from climate file for Atlanta

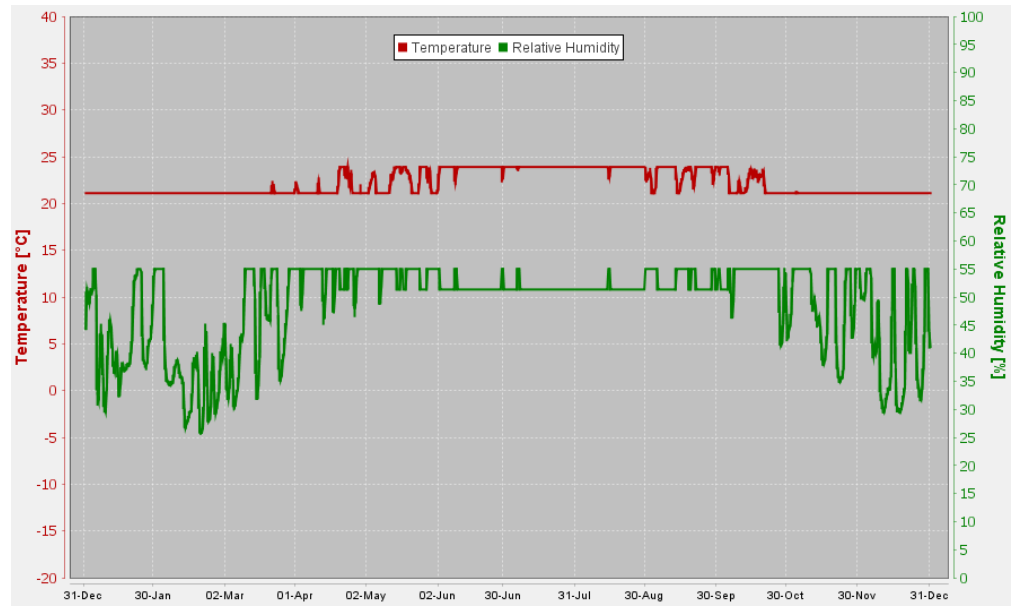

Figure 34: Indoor temperature and relative humidity for Atlanta 


\section{Baltimore}
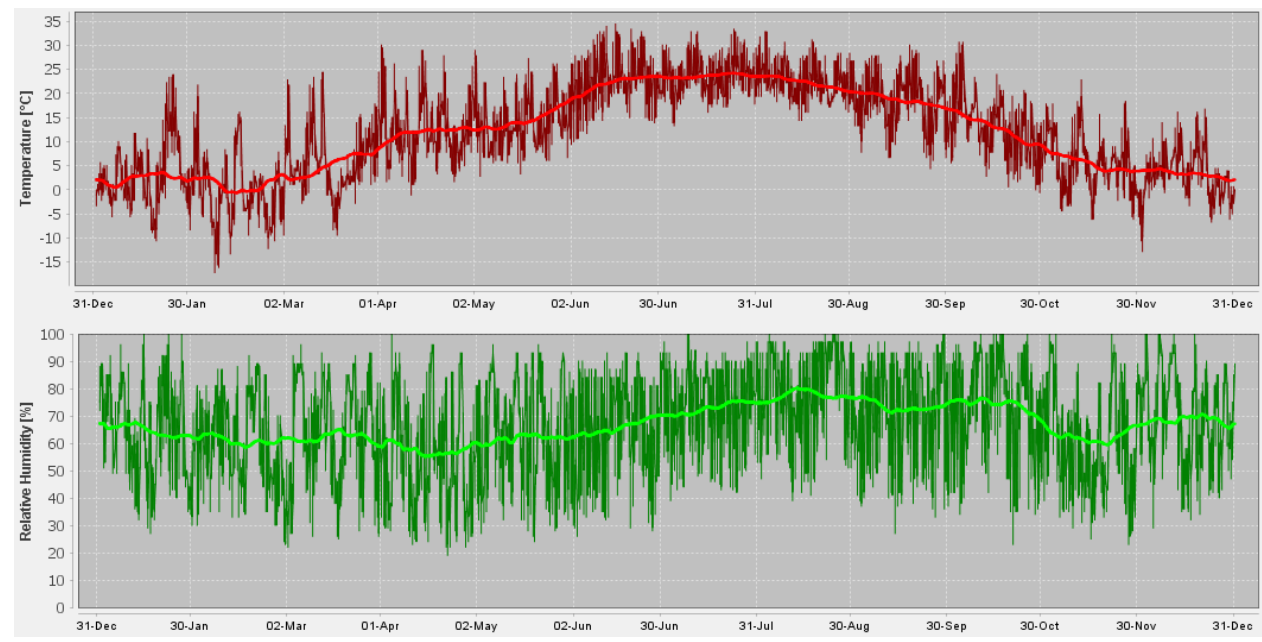

Figure 35: Exterior Temperature and relative humidity from climate file for Baltimore
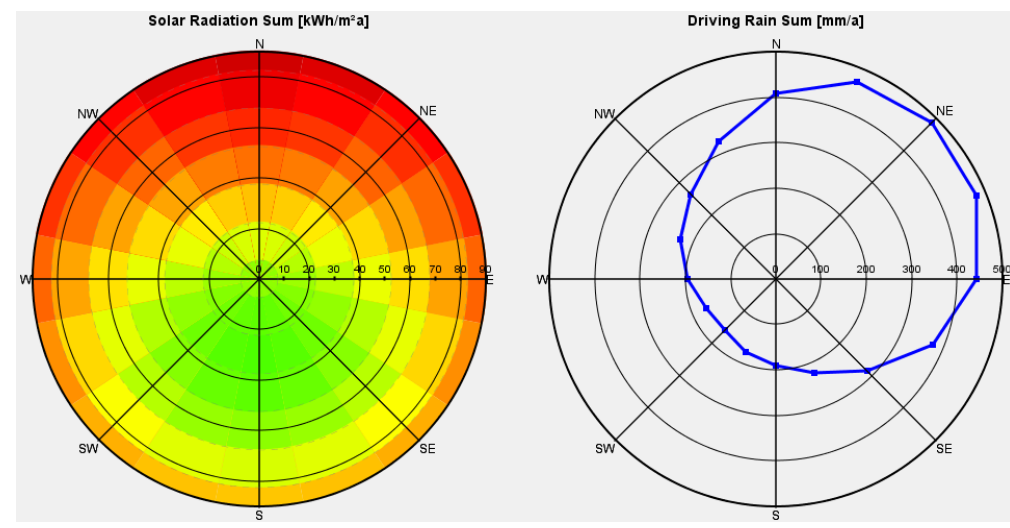

Figure 36: Solar and wind driven rain exposure from climate file for Baltimore

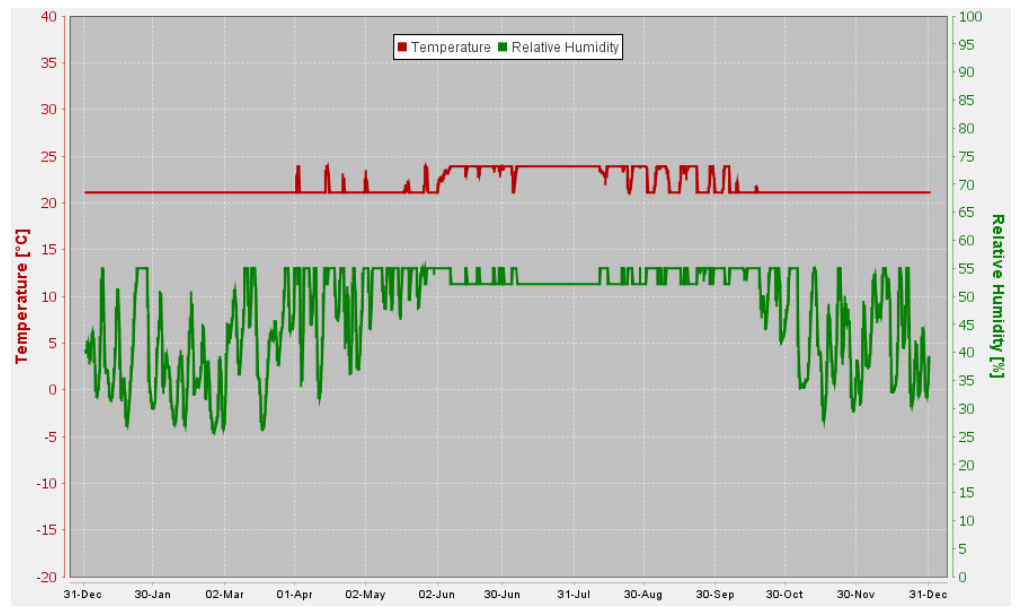

Figure 37: Indoor temperature and relative humidity for Baltimore 


\section{Seattle}
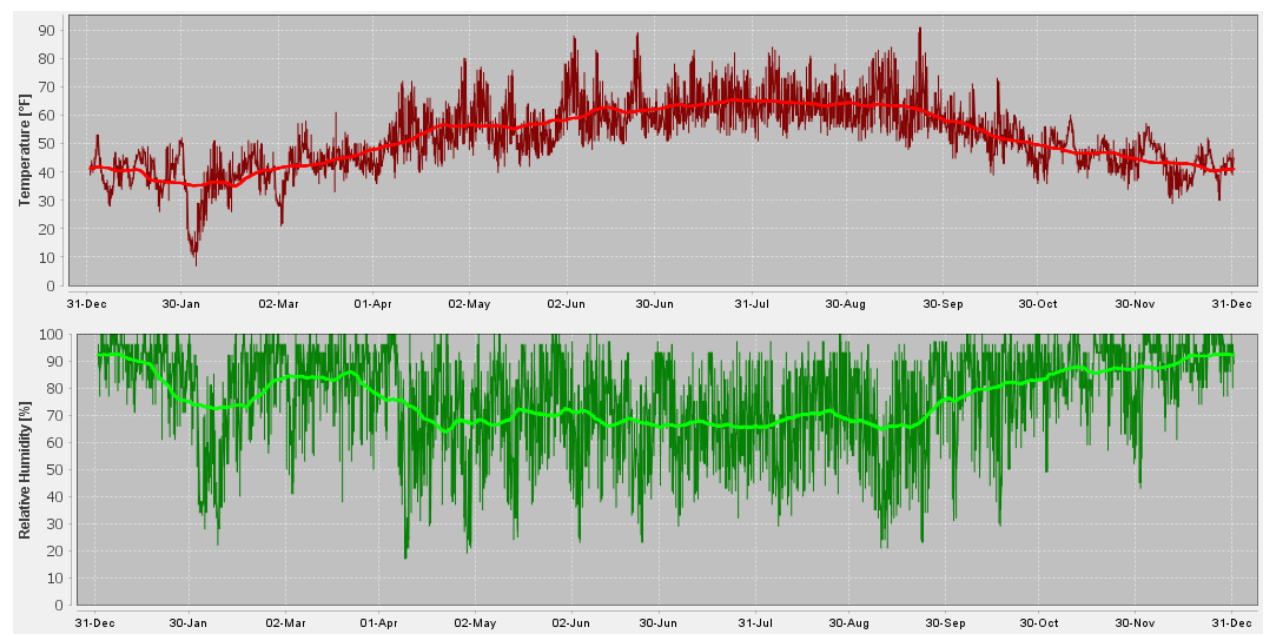

Figure 38: Exterior Temperature and relative humidity from climate file for Seattle
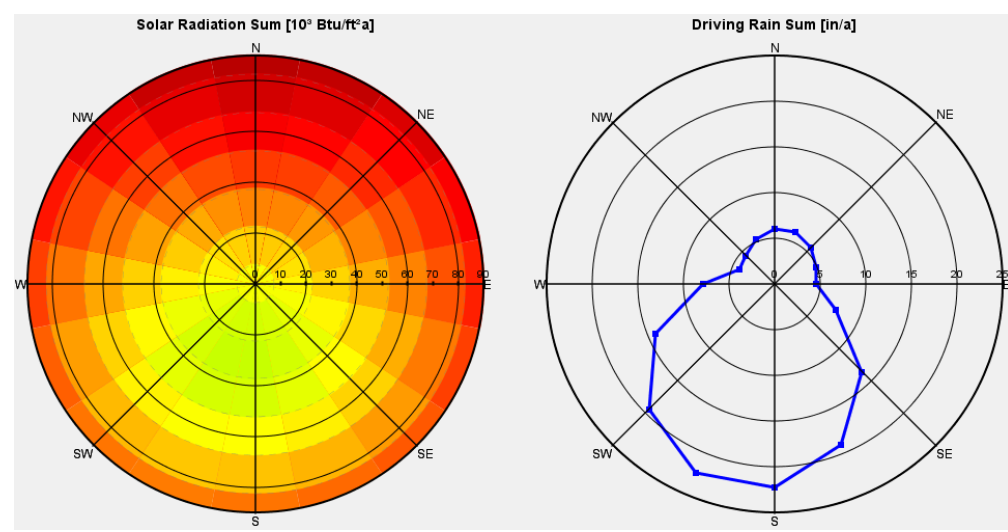

Figure 39: Solar and wind driven rain exposure from climate file for Seattle

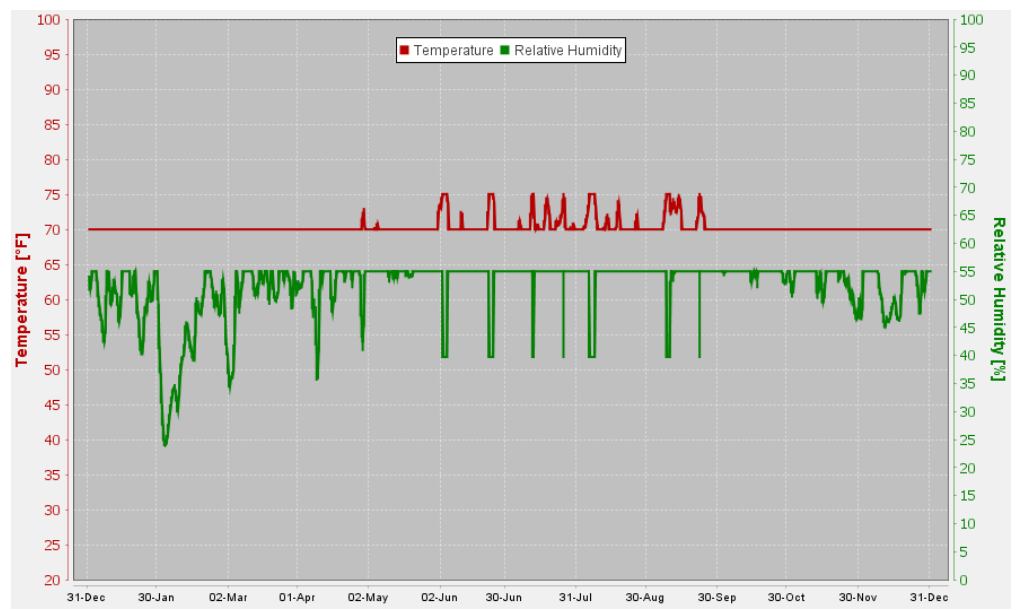

Figure 40: Indoor temperature and relative humidity for Seattle 